This manuscript is a post print of a published manuscript in Science of the Total Environment, available with DOI 10.1016/j.scitotenv.2020.140011 


\title{
Exposure and vulnerability estimation for modelling flood losses to commercial assets in Europe
}

\author{
Dominik Paprotny ${ }^{1}$, Heidi Kreibich ${ }^{1}$, Oswaldo Morales-Nápoles ${ }^{2}$, Attilio Castellarin ${ }^{3}$, \\ Francesca Carisi ${ }^{3}$ and Kai Schröter ${ }^{1}$ \\ ${ }^{1}$ Helmholtz Centre Potsdam, GFZ German Research Centre for Geosciences, Section \\ Hydrology, Potsdam, Germany. \\ ${ }^{2}$ Delft University of Technology, Department of Hydraulic Engineering, Delft, The Netherlands. \\ ${ }^{3}$ University of Bologna, DICAM, Water Resources, Bologna, Italy.
}

Corresponding author: Dominik Paprotny (paprotny@gfz-potsdam.de)

\begin{abstract}
Commercial assets comprise buildings, machinery and equipment, which are susceptible to floods. Existing damage models and exposure estimation methods for this sector have limited transferability between flood events and therefore limited potential for pan-European applications. In this study we introduce two methodologies aiming at improving commercial flood damage modelling: (1) disaggregation of economic statistics to obtain detailed building-level estimates of replacement costs of commercial assets; (2) a Bayesian Network (BN) damage model based primarily on post-disaster company surveys carried out in Germany. The BN model is probabilistic and provides probability distributions of estimated losses, and as such quantitative uncertainty information. The BN shows good accuracy of predictions of building losses, though overestimates machinery/equipment loss. To test its suitability for pan-European flood modelling, the BN was applied to three case studies, comprising a coastal flood in France (2010) and fluvial floods in Saxony (2013) and Italy (2014). Overall difference between modelled and reported average loss per company was only 2-19\% depending on the case study. Additionally, the BN model achieved better results than six alternative damage models in those case studies (except for one model in the Italian case study). Further, our exposure estimates mostly resulted in better predictions of the
\end{abstract}


damage models compared to previously published pan-European exposure data, which tend to overestimate exposure. All in all, the methods allow easy modelling of commercial flood losses in the whole of Europe, since they are applicable even if only publicly-available datasets are obtainable. The methods achieve a higher accuracy than alternative approaches, and inherently provide confidence intervals, which is particularly valuable for decision making under high uncertainty.

\section{Introduction}

Commercial assets encompass assets primarily used for economic activities by companies, government or non-profit institutions, as opposed to residential assets which pertain to activities of households (Eurostat, 2013). For the purposes of this study, the term "commercial" refers to buildings, machinery and equipment used for commercial and public purposes, but exclude public and private infrastructure, vehicles, and inventories. As such, commercial properties sustain substantial losses due to floods every year. In France, $32 \%$ of the value of insurance claims from the 2010 coastal flood was related to commercial properties, including agriculture (FFSA / GEMA, 2011). A similar percentage (28\%) was recorded after 2016 floods in the Loire and Seine river basins (Fédération Française de l'Assurance, 2017). Commercial losses comprised 29\% of total losses due to the 2007 summer floods in the United Kingdom (29\%), including indirect damages (Chatterton et al., 2010). In the Netherlands, the share of non-residential losses was even higher: $40 \%$ in the aftermath of the 1993 Meuse river flood and 52\% in the same area two years later (Wind et al., 1999). In the 2013 flood in Germany, companies suffered 19\% of the total 6.7 billion euro losses (Thieken et al., 2016). Those case studies show that the bulk of commercial losses was borne by companies in industry and services. A much smaller share of losses is in the governmental sector, and often the smallest in agricultural establishments, unless the affected area is predominantly rural, like in the case of the Meuse river floods. Additionally, commercial entities sustain much higher average losses than households, by a factor of two or three in the aforementioned cases.

Modelling exposure and vulnerability of commercial assets is difficult due to the large diversity of commercial units compared to households. They span a wide range of economic and institutional sectors, each with their own specific characteristics of buildings, machinery and equipment used. Many flood damage models are designed for use at the level of land-use patches 
rather than individual buildings (Gerl et al., 2016), hence the classification of commercial properties is based on particular land use typology (Jongman et al., 2012). The valuation of assets per land use area is then obtained from various sources, e.g. disaggregation of national/regional asset stocks or construction surveys (Seifert et al., 2010b). For estimating building-level exposure in Germany, Sieg et al. (2019a) proposed computing fixed asset stock per employee at the federal state level. Then, sampling the distribution of company sizes provides an estimate of the number of employees in commercial buildings identified in OpenStreetMap data. Still, consistent estimates of commercial property values beyond single countries are scarce, and the disaggregation methods are not easily transferable between countries due to different availability of economic, building and land-use data. Huizinga et al. (2017) provided construction costs per $\mathrm{m}^{2}$ for many European countries, separately for services and industry. However, those cover only buildings without machinery or equipment, and also are taken from two different construction cost surveys, which disagree even by a factor of two in their estimates.

Similarly to exposure, various classifications of commercial buildings have been used in damage modelling, often related to land-use classes and created as synthetic models rather than based on empirical data (De Moel and Aerts, 2011; Gerl et al., 2016, Keller et al., 2019). Many damage models are univariate damage curves for particular economic activity or building type (ICPR, 2001; Kok et al., 2005; Reese et al., 2003), including one synthetic model intended for panEuropean applications (Huizinga, 2007). Extensive look-up tables were developed for the United Kingdom (Penning-Roswell et al., 2013), based on a synthetic approach, i.e. using information acquired by building experts via what-if-questions, and provide absolute damage estimates, making them difficult to apply to other countries. So far, the largest source of detailed empirical data on commercial losses at building level is the German databank HOWAS21, containing in particular information from post-disaster surveys covering flood events going back to 1978 (Kellermann et al., 2020). This unique dataset was first used to develop FLEMOcs model, which is a multi-variable model in the form of look-up tables (Kreibich et al., 2010; Seifert et al., 2010a). Subsequently, Sieg et al. (2017; 2019a; 2019b) used a data-mining method known as Random Forests to develop a new multi-variable model from extended German survey data. It includes four economic activity sectors (industry and three subdivisions of services) and three types of assets (buildings, equipment, goods and stock). 
Availability of open spatial data is increasing steadily, enabling new means of quantifying exposure and application of damage models (Sieg et al., 2019a, Jato-Espino et al., 2019). Presently, OpenStreetMap (2020) provides crowd-sourced data on buildings, sometimes also integrated from publicly-available administrative sources. Even if availability of detailed characteristics of those buildings (such as function and size) varies between locations, this resource can lead to a standardized approach in estimating exposure to commercial assets in Europe, which is currently lacking (Gerl et al., 2016; Bremond et al., 2013). Further, models for universal, pan-European flood assessments would require validation in various environments, both natural (such as different flood types) and socio-economic (different type and values of assets), as attempted previously by Jongman et al. (2012).

New methods of data analysis and modelling enable tackling some of the limitations of existing flood damage models (Merz et al., 2013; Schröter et al., 2014; Wagenaar et al., 2018). One problem with multi-variable models using look-up tables and Random Forests is their inflexibility to missing data. The models are based on survey data, and it is often impossible to gather the required variables for actual implementation of the models to case studies (Apel et al., 2009; Gerl et al., 2014; Schröter et al., 2018). Another problem is that the models are often deterministic, rather than probabilistic, hence they don't provide uncertainty bounds of their estimates. This is addressed e.g. by the aforementioned Random Forests method using an ensemble approach, but still without the flexibility to work under missing local information. Here, we address those limitations using Bayesian Networks, a graphical and probabilistic method for modelling complex dependency structures (Hanea et al., 2006; 2015), which could be used flexibly depending on actual data availability in local applications.

This paper aims at advancing the current methodologies of commercial damage estimation in flood risk assessments, and creating probabilistic models suitable for pan-European applications using only openly-available data. It combines data and methods from the domain of both hydrosphere (flood hazard modelling) and anthroposphere (economic valuation of exposure and losses), both important components of flood risk analyses (Kazakis et al., 2015; Bathrellos et al., 2017). We hypothesize that using a Bayesian Network approach combined with novel use of openly-available spatial and statistical data can improve commercial flood loss estimation in Europe. 
The manuscript is organized as follows (Fig. 1). A building-level probabilistic damage model, created on the basis of a unique resource in the form of German post-disaster surveys (section 2.1.1), is introduced in section 2.1.2. A transferable method of building-level exposure estimation for European countries is proposed in section 2.2. The damage estimates are validated (section 2.3) for different flood events and economic sectors (section 3.1). The full procedure is carried out for case studies of a coastal flood in France and fluvial floods in Germany and Italy (section 3.2) and compared with alternative, previously published models. The paper finishes with a discussion of limitations and uncertainties (section 4) as well as conclusions (section 5).

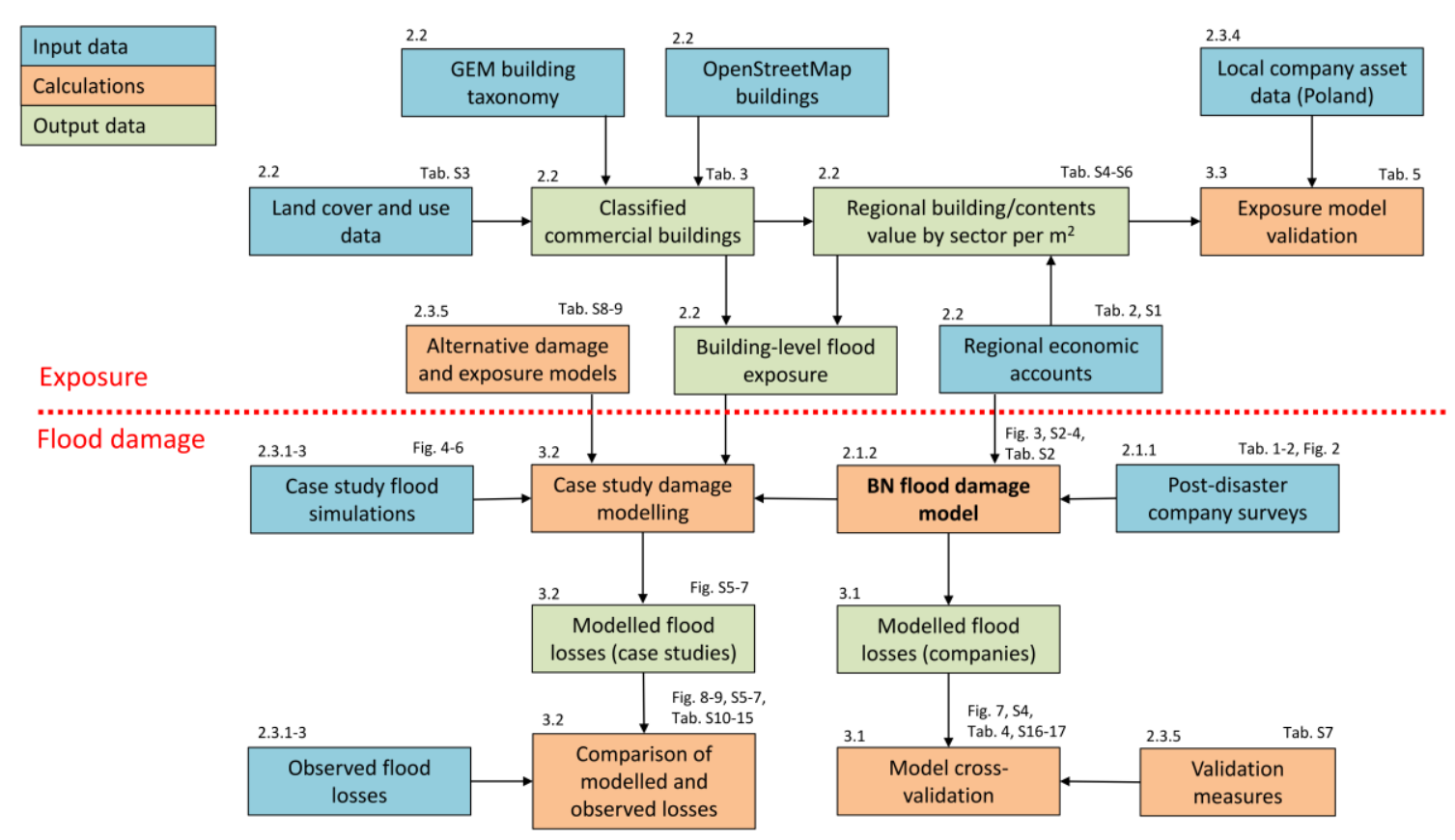

Figure 1. Flowchart of the study. The numbers in the upper left corners of the boxes refer to sections of the paper.

\section{Materials and Methods}

2.1 Commercial damage modelling

\subsubsection{German post-disaster company surveys}

Empirical flood damage data of the commercial sector were collected in five surveys made between 2003 and 2014 in Germany, covering events from seven different years. In those surveys, randomly-selected companies affected by floods were interviewed by a professional surveying 
company. The exact composition of the questionnaire varied between surveys, but cover mainly flood intensity (e.g. water depth and inundation duration), company characteristics (e.g. economic activity type, turnover, size of premises, number of employees), monetary value of assets (buildings, contents, stocks) and the value of damages sustained, the use of precautionary and emergency measures, and previous flood experience. For detailed methodology of survey data collection and processing we refer to Kreibich et al. (2007) and Thieken et al. (2017).

The dataset contains 1346 records. Most of those are losses sustained by companies during two major summer fluvial floods, from August 2002 (Engel, 2004) and June 2013 (Schröter et al., 2015), with 479 and 557 records, respectively. A further 163 records (surveyed in 2006) pertain to the rainfall-induced flood on August 2005 (Bayerisches Landesamt für Umwelt, 2007) and spring thaw flood of April 2006 (Bundesanstalt für Gewässerkunde, 2006). The final 147 data points (surveyed in 2013) refer to numerous smaller floods that occurred between January 2010 and May 2013, particularly to a rapid rainfall-induced flood of August 2010 (Polnisch-deutsch-tschechische Expertengruppe, 2010) and a snowmelt flood of January 2011 (Axer et al., 2012). The location of all records inside Germany is presented in Figure 2.

The largest share of surveyed companies was active in NACE (Statistical Classification of Economic Activities in the European Community) sectors G-I, which covers mainly trade, transportation, accommodation and food services (see Supplementary Table S1 for detailed explanation of NACE sectors). Industry (incl. utilities and construction) was the second-most represented sector (B-F). Slightly less companies were in sectors O-U, covering mainly public services such as administration, health and education, but also entertainment and recreation. Further companies were in sectors J-N, which includes e.g. professional services, finance, real estate and communication. Only a small number of companies belonged to the agricultural sector (A). 
Post print of a paper in Science of the Total Environment, DOI 10.1016/j.scitotenv.2020.140011

Table 1. Data points available from German company post-disaster surveys by year and economic sector. NACE - Statistical Classification of Economic Activities in the European Community (Eurostat, 2013). For explanation of sectors see Supplementary Table S1.

\begin{tabular}{|l|l|r|r|r|r|r|r|}
\hline \multirow{2}{*}{$\begin{array}{c}\text { Year of } \\
\text { event }\end{array}$} & \multirow{2}{*}{ Year of survey } & \multicolumn{6}{|c|}{ Data points by NACE (rev. 2) sector } \\
\cline { 3 - 8 } & & Total & A & B-F & G-I & J-N & O-U \\
\hline 2002 & $2003 / 2004 / 2006$ & 479 & 8 & 163 & 187 & 67 & 54 \\
\hline 2005 & 2006 & 102 & 4 & 22 & 37 & 13 & 26 \\
\hline 2006 & 2006 & 61 & - & 8 & 20 & 10 & 23 \\
\hline 2010 & 2013 & 60 & 2 & 9 & 23 & 6 & 20 \\
\hline 2011 & 2013 & 58 & 3 & 7 & 27 & 1 & 20 \\
\hline 2012 & 2013 & 21 & 1 & 2 & 12 & 1 & 5 \\
\hline 2013 & $2013 / 2014$ & 565 & 14 & 108 & 201 & 104 & 138 \\
\hline Total & & 1346 & 32 & 319 & 507 & 202 & 286 \\
\hline
\end{tabular}




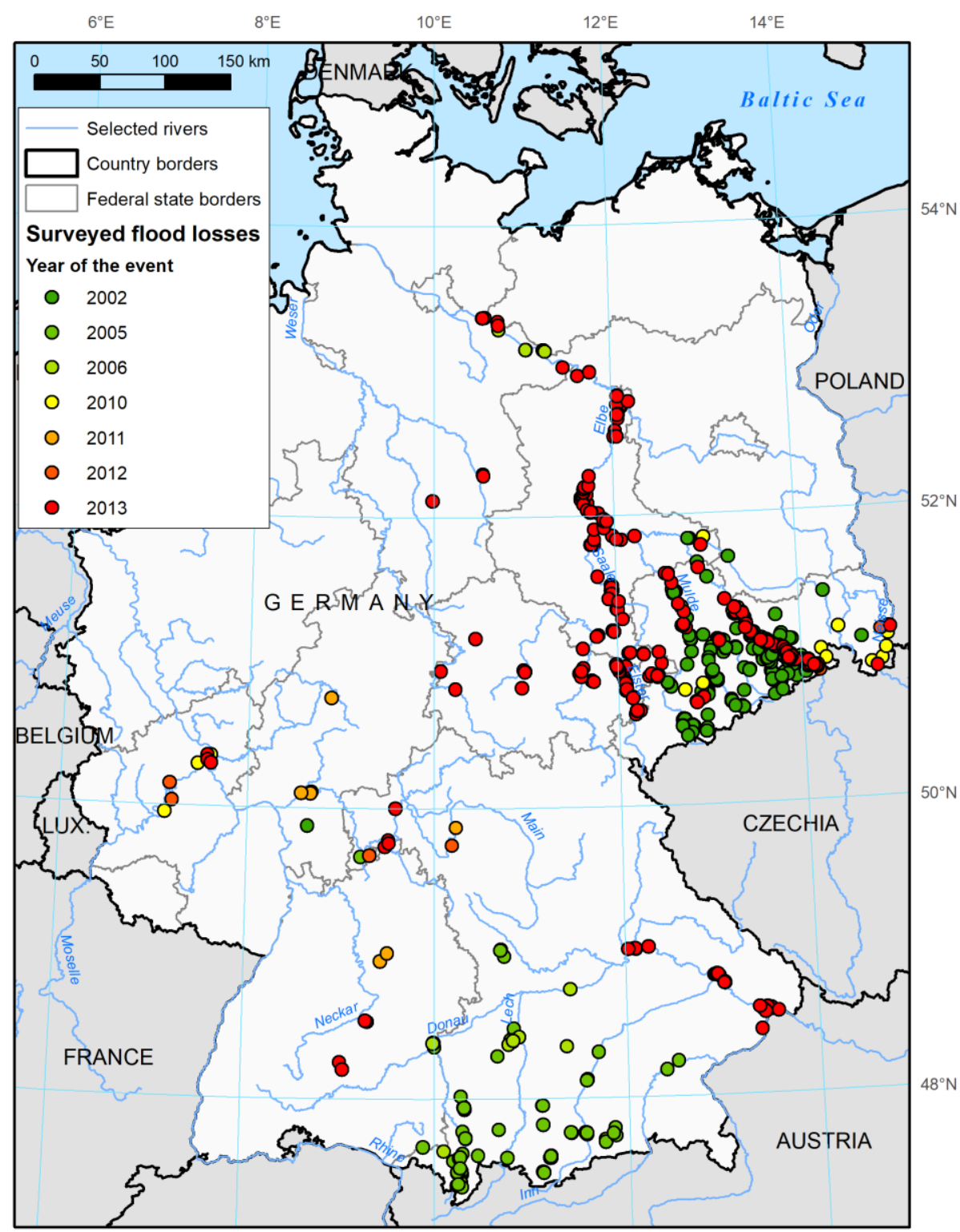

Figure 2. Location of surveyed flood losses. Borders from Eurostat (2020b), rivers from CCM2 dataset (Vogt et al., 2007).

\subsubsection{A Bayesian Network-based flood damage model}

The German flood survey data were used to build a flood damage model for commercial properties. It utilizes Bayesian Networks (BNs). To the authors' knowledge, no study has ever used any type of BNs for modelling commercial flood losses. The particular variant of BNs used here are nonparametric BNs. The method uses empirical marginal distributions and, in this application, a 
Gaussian copula as the dependency model for obtaining conditional probability distributions. Nonparametric BNs were originally introduced by Kurowicka \& Cooke (2006) and further described by Hanea et al. $(2006 ; 2015)$. This method uses only continuous variables, hence discrete variables from the flood survey data had to be excluded from the analysis. A hybrid discrete-continuous is also possible, but due to much larger availability of continuous variables, we chose not add this additional level of computational complexity. The configuration of the model structure is driven by expert knowledge, supported by the (conditional) correlations between variables.

The assumption of a Gaussian copula can be tested in two ways. First, the fit of several copula types was analysed with a "Blanket Test" by Genest et al. (2009). The statistic $M$ for a sample of length $n$ is computed as follows (eq. 1):

$$
M_{n}(\boldsymbol{u})=n \sum_{|\boldsymbol{u}|}\left\{C_{\widehat{\theta}_{n}}(\boldsymbol{u})-B(\boldsymbol{u})\right\}^{2}, \boldsymbol{u} \in[0,1]^{2}
$$

where $B(\boldsymbol{u})=\frac{1}{n} \sum_{i=1}^{n} \mathbf{1}\left(U_{i} \leq \boldsymbol{u}\right)$ is the empirical copula and $C_{\widehat{\theta}_{n}}(\boldsymbol{u})$ is a parametric copula with parameter $\hat{\theta}_{n}$ estimated from the sample. The test shows that different (unconditional) variable pairs chosen for the model are best represented by different copulas (Supplementary Figure S1), but the average score for the Gaussian copula is better than for tail-dependent Gumbel or Clayton copulas. Further, Morales-Nápoles et al. (2014) and Hanea et al. (2015) postulated that the joint distribution of a given non-parametric BN structure is uniquely determined. Hence, they proposed a "d-calibration" test to the validity of a normal copula for a particular BN structure, which is presented in Supplementary Figure S2. The determinant of the empirical rank correlation matrix of the selected variables falls within the $90 \%$ confidence interval of the determinant of an empirical normal distribution (Supplementary Figure S2). This means that a normal copula is a valid assumption for the joint distribution of the variables. However, the determinant of the rank correlation matrix of the final BN model is outside the $90 \%$ confidence interval of the determinant of the random normal distribution sampled for the same correlation matrix. This indicates that the joint normal copula is not valid for the particular configuration of the $\mathrm{BN}$, though this d-calibration test is rather severe.

Ten variables were extracted from the surveys, comprising all continuous variables contained in the surveys that could be expected to be available for implementation of the model in case studies. Some variables were excluded because they were not collected for all surveys (e.g. flow velocity, business turnover before the flood, building/equipment age). Certain discrete 
variables were shown relevant (at least for some types of economic activity) for commercial loss estimation by Sieg et al. (2017), mainly water contamination, the number of employees and the type of premises occupied, but in practice it was not possible to collect such microdata for actual test cases (Sieg et al., 2019a,b).

Additional nine variables describing regional economic conditions were obtained from Eurostat (2020a) database (Table 2). Two continuous quantities related to hazard intensity were available: water depth and inundation duration. Information on exposure was recorded in the flood surveys as size of premises and the monetary value of buildings and machinery/equipment. The value of the inventories held by companies, and damages to those, was also available from the surveys, but was not analysed here. This is due to the limited possibility of estimating exposure to this category of assets using openly available data for an actual application of the model, as will be discussed in section 2.2. The values of buildings and machinery/equipment from different years were converted to euros at 2015 price levels using national deflators for non-residential buildings and machinery/equipment from Statistisches Bundesamt (2019).

Economic situation of regions, defined using NUTS (Nomenclature of Territorial Units for Statistics) classification, was computed from data on gross value added (GVA), gross fixed capital formation (GFCF), compensation of employees as well as total employment and population. Four indicators were used in two versions: the total value of the indicator in a given region, or the value corresponding to a particular NACE sector, the same as the company's profile indicated in the survey data. All economic indicators were computed for the year of the flood event that affected each company, but in euro in constant prices (reference year 2015). Indicator-specific deflators were utilized, except for compensation for employees, which was deflated using the consumer price index. 
Table 2. Candidate variables for the Bayesian Network-based flood damage model for commercial properties.

\begin{tabular}{|l|l|l|}
\hline \multicolumn{1}{|c|}{ Variable } & \multicolumn{1}{c|}{ Unit } & Source \\
\hline Hazard & & \\
\hline Water depth relative to ground level & $\mathrm{cm}$ & Survey \\
\hline Inundation duration & $\mathrm{h}$ & Survey \\
\hline Exposure & & \\
\hline Size of premises & $\mathrm{m}^{2}$ & Survey \\
\hline Building value & euro & Survey \\
\hline Machinery and equipment value & euro & Survey \\
\hline Gross value added (GVA) per capita by NUTS3 region & euro & Eurostat \\
\hline GVA per person employed by NUTS3 region* & euro & Eurostat \\
\hline Gross fixed capital formation (GFCF) per person employed by NUTS2 region* & euro & Eurostat \\
\hline GFCF as \% of GVA by NUTS2 region* & euro & Eurostat \\
\hline Compensation of employees per employee by NUTS2 region* & euro & Eurostat \\
\hline Vulnerability and consequences & & \\
\hline Precautionary measures indicator & - (fraction [0,1]) & Survey \\
\hline Total damage to building structure & euro & Survey \\
\hline Total damage to machinery and equipment & euro & Survey \\
\hline Relative damage to building structure & - (fraction [0,1]) & Survey \\
\hline Relative damage to machinery and equipment & - (fraction [0,1]) & Survey \\
\hline
\end{tabular}

Note: * in two variants: total for all sectors and per specific NACE sector corresponding to the company's profile.

In the domain of vulnerability, the use of precautionary measures is converted into a synthetic indicator. This indicator is the percentage of possible precautionary measures actually applied by companies before the flood relative to the total number of possible measures. The latter number is not fixed because some measures might be not applicable to a particular company. As a result, the indicator is continuous rather than discrete. Ten possible measures are included in the indicator: (1) adapted use of the flood prone area; (2) relocation of susceptible equipment; (3) relocation of dangerous substances; (4) flood-proof oil tanks; (5) flood-proof silos; (6) flood-proof air conditioning; (7) stable building foundation, waterproof-sealed cellar, etc.; (8) installation of water barriers; (9) company emergency plan; (10) company emergency exercises. Finally, total damages sustained by the companies were derived, separately for buildings and machinery/equipment. Divided by the total amount of assets held by the companies, relative loss 
was obtained. On occasion, the respondents indicated more damages than the value of assets exposed. In such cases the relative damages were set to " 1 " (complete loss).

The flood damage model was created from the variables listed in Table 2 . The variables of interest are relative damages to buildings and machinery/equipment, while 15 variables could potentially explain their intensity. In the first step, an unconditional rank correlation matrix was computed (Supplementary Table S2). It shows that the correlation between water depth and relative loss is the strongest. The dependency structure was then expanded by analysing the conditional rank correlations between relative loss and explanatory variables, as well as the (conditional) correlations between the explanatory variables. Further, only those dependencies between variables that could be explained on a theoretical level were included in order to avoid spurious links (e.g. between economic situation in the region and hazard intensity). In the process, a model to estimate relative loss to buildings (brloss) and machinery/equipment (erloss) with five explanatory variables was constructed (Figure 3). The final BN rank correlation matrix is shown in Supplementary Figure S3. The choice of variables and dependency structure is explained as follows:

- Water depth relative to ground level (wst) is correlated with relative losses, because higher water levels affect a greater proportion of the structure of a building and can reach a higher share of the machinery and equipment inside, which is located at different floors (including basement) and heights above floor. Water depth was found to be the most important factor explaining commercial flood losses in other multi-variable analyses (Kreibich et al., 2010; Sieg et al., 2017).

- Inundation duration (d) further increases losses to the building structure, though it was not relevant for machinery and equipment loss. Long contact of the building with standing water leads to further deterioration of the structure, including through the process of capillary rise (Kelman \& Spence, 2004). Duration was included in the damage model MCM (Penning-Roswell et al., 2013) and the Random Forest-based model by Sieg et al. (2017). Duration is correlated with water depths, as areas under relatively deep water would take more time to dry compared to those under shallow water.

- Precautionary measures indicator (pre_ratio) is negatively correlated with relative loss to machinery and equipment. Two effects can be discerned here: (1) the more measures the company has implemented before the flood, the less water was able to reach the machinery 
and equipment; (2) the fewer measures were applicable to a particular company (increasing the value of the indicator as long as any measure was deployed), the lower was the exposure and/or vulnerability of the company (e.g. no oil tanks, air-conditioning systems, or no susceptible equipment). As the list of possible measures includes mostly items that would protect the machinery and equipment rather than the building, hence the indicator was found not relevant for building loss prediction. The use of precautionary measures, in the form of different synthetic indicators, was included in other commercial loss models based on the German survey data (Kreibich et al., 2010; Sieg et al., 2017). The indicator is correlated with regional gross value added per capita, as companies in richer regions could be expected to have more money to invest in precautionary measures than those in poorer regions.

- Gross value added (GVA) per capita by NUTS3 region (NUTS3_GVApc) has relevance for relative losses to both buildings and machinery/equipment. As the positive correlation with the use of precautionary measures, companies in richer regions could be more able to afford an improvement to their flood resilience than those in poorer regions. GVA is correlated with gross fixed capital formation, as it is one of the components of GVA.

- Gross fixed capital formation (GFCF) per person employed by NUTS2 region (NUTS2_GFCFpe) further reduces damages to buildings. A significant part of GFCF is investment in buildings, therefore higher levels of those should result in more modern and resilient constructions.

- Relative damage to building structure (brloss) is still highly correlated with relative loss to machinery and equipment (erloss) after including all previous factors. This indicates that higher losses to the building structure go in pair with higher contents loss, possibly due to factors not considered in the dataset, e.g. flow velocity, water contamination or flood warning lead time. 


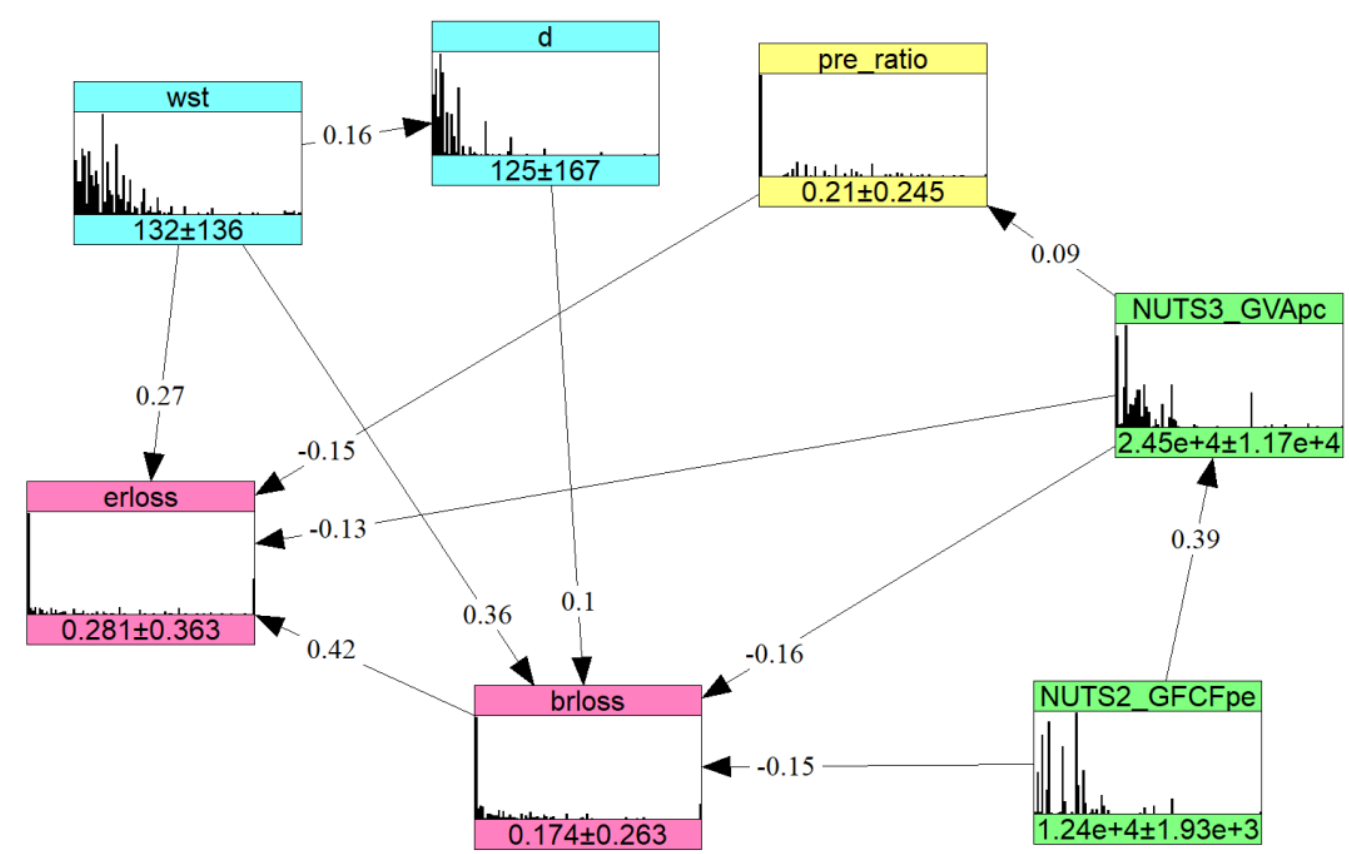

Figure 3. A Bayesian Network for predicting commercial flood losses. Values on the arcs represent the (conditional) rank correlation; values under the histograms are the mean and standard deviation of the marginal distributions. Only complete records were used to compute the histograms and correlations here. Graph generated using Uninet software (Hanea et al., 2015).

\subsection{Commercial exposure estimation}

The general concept of estimating exposure at the level of individual commercial buildings applied here is disaggregating asset values based on the size and occupation of OpenStreetMap (OSM) buildings. OSM provides building polygons, often together with explicit or implicit information on their function. Further information on the use of buildings can be gathered from land use data also contained in OSM. To uniformize the various descriptors of OSM, we use Building Taxonomy 2.0 developed for the Global Earthquake Model (GEM) (Brzev et al., 2013). The reclassification of OSM buildings to GEM taxonomy was prepared at GFZ Section 2.6 (Seismic Hazard and Risk Dynamics) based on OSM data as of 8 March 2018.

GEM classified buildings were then assigned to NACE economic activity sectors, which are used in economic statistics. Given the relative coarseness of both economic data and the building taxonomy, six NACE sectors were used. The sectors are the same as in the German survey data 
(section 2.1), except for the sector O-U, containing mostly public services, which was split into two (O-Q and R-U). The assignment of buildings to sectors is shown in Table 3.

Asset values defined as the gross stock (i.e., without depreciation) in current replacement costs are available from Eurostat database for 22 European countries, split by basic asset types and economic activities (Eurostat, 2020a). More countries publish asset data nationally, often with greater level of detail (including regional asset stocks, more detailed subdivisions of assets and activities). In context of the German survey data, the relevant categories of assets according to the European System of Accounts 2010 are as follows (Eurostat, 2013):

- Buildings other than dwellings (AN.1121) - for estimating commercial building value;

- ICT equipment (AN.1132) and other machinery and equipment (AN.1139) - for estimating commercial machinery and equipment.

For consistency with the survey data, transport equipment (AN.1131) is excluded. Outside the scope are also cultivated biological resources (AN.115), a category almost exclusive to the agricultural sector. Structures other than buildings (other structures - AN.1122 and land improvements - AN.1129) should also be excluded, however Eurostat only publishes data at higher level of aggregation (other buildings and structures - AN.112). Not all countries publish the more detailed data nationally, so assumptions have to be made for those to avoid overestimation especially in sectors G-I and O-Q, which contain e.g. public roads, railways or military installations. Also, we omit the "goods and stocks" category shown separately in the survey data. This is because the nearest equivalent in national accounts are inventories (AN.12), which contain not only materials, supplies, finished goods and goods for resale, but also work-in-progress (e.g. unfinished buildings) and military inventories. Additionally, few countries publish data on inventories, and even fewer provide them split by economic activity. 
Table 3. Assignment of OSM buildings by GEM occupancy to economic activity sectors (NACE). For explanation of sectors see Supplementary Table S1.

\begin{tabular}{|l|l|l|}
\hline \multicolumn{1}{|c|}{$\begin{array}{r}\text { GEM occupancy } \\
\text { codes }\end{array}$} & & Economic activity (NACE) \\
\hline AGR* & Agricultural buildings & A \\
\hline ASS* & Assemblies (arena, cinemas, concert halls, churches, etc.) & R-U \\
\hline COM1, COM2 & Retail, wholesale, storage & G-I \\
\hline COM3 & Offices, professional/technical services & J-N \\
\hline COM4 & Hospital & O-Q \\
\hline COM5 & Entertainment & R-U \\
\hline COM6 & Public building & O-Q \\
\hline COM7-COM10 & Garage, bus and railway station, airport & G-I \\
\hline COM11 & Recreation and leisure & R-U \\
\hline COM99 & Commercial and public, unknown type & G-I, J-N, O-Q, R-U** \\
\hline EDU*, GOV* & Education, government & O-Q \\
\hline IND* & Industry & B-F \\
\hline MIX1, MIX2 & Mixed residential and commercial & G-I, J-N, O-Q, R-U** \\
\hline MIX3, MIX5, MIX99 & Mixed commercial and industrial, mixed unknown type & B-F, G-I, J-N, O-Q, R-U** \\
\hline MIX4, MIX6 & Mixed residential and industrial & B-F \\
\hline OC99 & $\begin{array}{l}\text { Unknown occupation }- \text { the footprint area was distributed } \\
\text { proportionately to known footprints areas by occupation. }\end{array}$ & - \\
\hline
\end{tabular}

Note: * all codes in the category; ** disaggregated proportionately to share of the sectors indicated in combined GVA.

Asset stocks at national (or, for some countries - regional) level are transformed into a ratio by dividing them with the gross value added (GVA) per given economic activity. Then, this ratio is used to estimate the asset values at the level of NUTS3 regions. These are the most detailed country subdivisions at which national-accounting is carried out. Currently, Eurostat provides NUTS3 economic data for 33 countries (Eurostat, 2020a), with more data available from national statistical institutes. Once regional GVA is obtained from those sources, it is multiplied by the asset-to-GVA ratio from the national (or, upper regional) tier.

Regional estimate of the asset stock is the basis for disaggregation to OSM buildings. For each economic activity, the total footprint area of corresponding OSM buildings is calculated. For commercial and public buildings of unknown type and mixed use, the structure of the companies' footprint area was assumed to follow the distribution of GVA by economic activity. In the case of 
buildings with unknown occupation, the footprint area was distributed proportionately to those footprint areas by occupation already identified in OSM. Then, the value of assets is calculated per

$\mathrm{m}^{2}$ building footprint area, and assigned back to OSM buildings by occupancy. In this way, building-level commercial exposure values can be achieved, separately for buildings and machinery/equipment, for each region, using eight groups of occupancy types. We apply this methodology to the case studies described in section 2.3.

2.3 Testing and validating the flood damage modelling approach

\subsubsection{Validation case study: 2010 coastal flood in France}

The performance of the exposure and damage modelling routines was tested first in an area very different from the one contained in the German survey data. This case study aims at modelling losses sustained on $28^{\text {th }}$ February 2010 in western France, when a major storm surge generated by extra-tropical storm Xynthia caused extensive damages and loss of life (Bertin et al., 2012; Vinet et al., 2012; Kolen et al., 2013). The extent of damages is known from insurance claims filed after the event (FFSA / GEMA, 2011). The total number of claims related to the flood in the commercial sector was estimated at 5500, of which 1700 in the agricultural sector. The value of those claims was 235 million euro, of which 26 million euro in agriculture. In the most severely affected departments of Charente-Maritime and Vendée (Figure 4) there were approximately 2910 and 630 claims, respectively, worth 185 and 21 million euro (FFSA / GEMA, 2011). More detailed sectoral and spatial split of the losses was not available.

Exposure during the 2010 event was estimated firstly by obtaining OSM data for the whole departments of Charente-Maritime and Vendée, as they constitute NUTS3 regions with corresponding economic data. Regional GVA was extracted from Eurostat's database (2020a) and the national stock of assets from the national statistical institute INSEE (2018). However, the occupation for $32 \%$ of buildings by footprint area in Charente-Maritime and $38 \%$ in Vendée couldn't be identified by OSM data alone. Therefore, the data was amended using land cover/use data for the metropolitan regions of La Rochelle and Niort from Urban Atlas 2012 (Copernicus Land Monitoring Service, 2019a) and for the remaining area from Corine Land Cover 2012 (Copernicus Land Monitoring Service, 2019b). Assignment of GEM occupancy codes to land cover/use classes is shown in Supplementary Table S3. The additional data reduced the share of unknown occupation to $23 \%$ and $32 \%$ for the two regions. The amended building dataset was used 
for disaggregation of economic assets as outlined in section 2.2. The results are presented in Supplementary Table S4.

OSM was likewise used to identify buildings affected by the event. Commercial buildings located within the observed flood extent (Bertin et al., 2014) were relatively few using OSM data directly (408). As many residential buildings have services on their ground floors, OSM data on amenities were used to reclassify residential buildings into commercial, if the buildings contained any amenities (171 cases). Urban Atlas land cover/use data for La Rochelle area added classification of 623 buildings (as per Supplementary Table S3). Finally, 180 agricultural buildings were added using Corine Land Cover data. In contrast to the asset disaggregation in the previous paragraph, population per grid cell had to equal zero in order to assign agricultural use to OSM buildings with unknown occupation. This was done to minimize possible error of misclassifying residential buildings as agricultural. The total number of commercial buildings identified is 1382 , or less than quarter of the number of insurance claims.

As a final step, data for the damage model were collected. Water depths were obtained by merging results of two hydrodynamic simulations: a broader one for the whole study area by Bertin et al. (2014) and a more detailed one focused on La Faute-sur-Mer municipality by Huguet et al. (2018), which was the most severely affected municipality. Both simulations involved a 2D model SELFE coupled with spectral wave model WWMII (Roland et al., 2012) and an unstructured grid of varying resolution. Unfortunately, information on inundation duration or the use of precautionary measures was not available, hence those nodes of the Bayesian Network model were left unconditionalized, i.e. the prior distribution from the learning sample was assumed in all cases. Finally, regional economic data was obtained from Eurostat (2020a), though regional GFCF data going back to 2010 are no longer obtainable. Consequently, 2014 regional GFCF per person employed was extrapolated back to 2010 proportionately to the change of this indicator at national level, which was nonetheless negligible (0.3\% in constant prices). GVA per capita in 2010 in 2015 constant prices was 21,459 euro in Charente-Maritime and 22,871 euro in Vendée, while GFCF per person employed was 15,087 and 15,555 euro in corresponding NUTS2 regions PoitouCharentes and Pays de la Loire, respectively. The water depth data didn't indicate flooding for all identified commercial buildings, hence the final number of data points used in the analysis was 1006. 


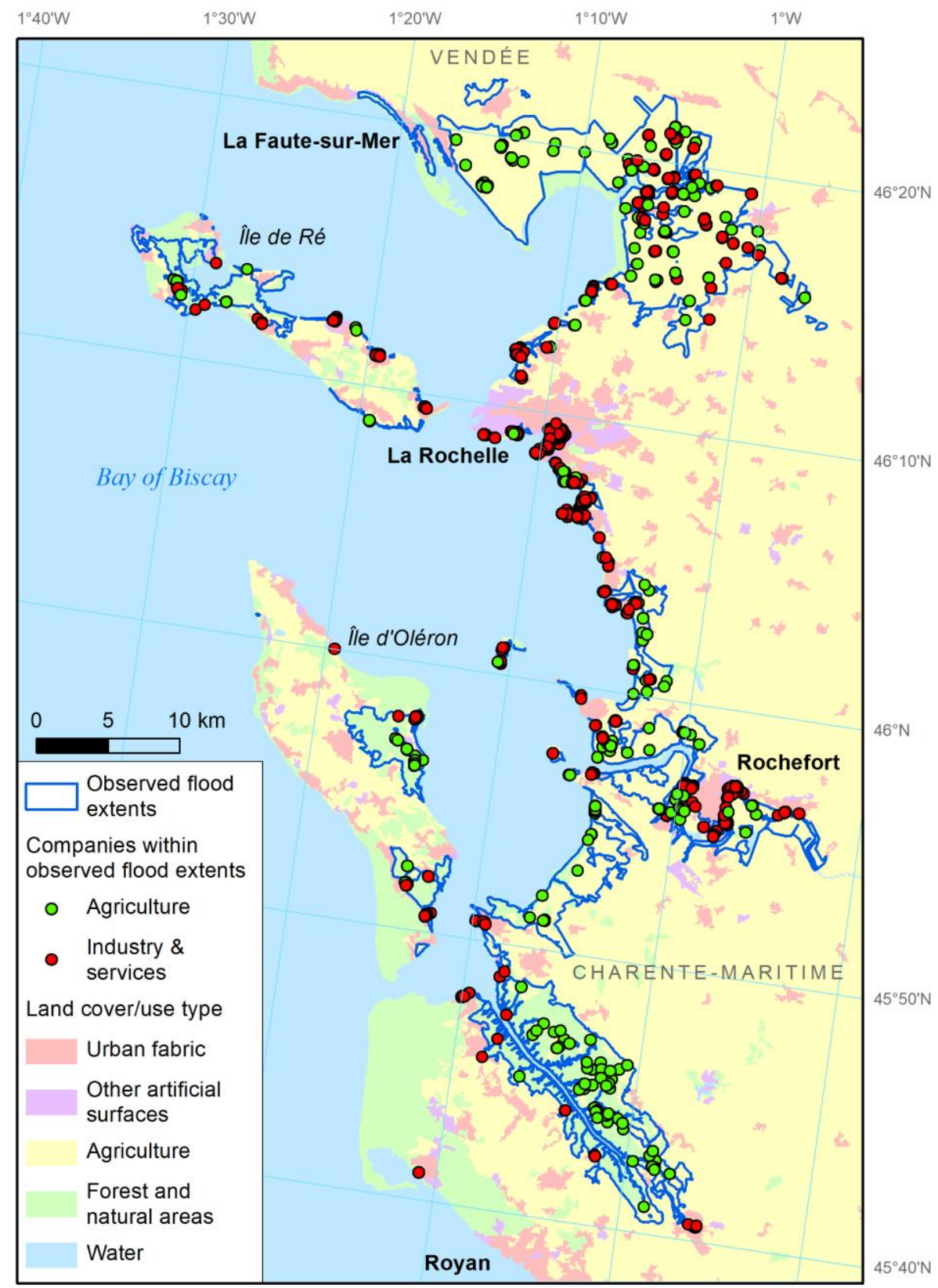

Figure 4. Observed flood extents and companies identified through OpenStreetMap (with supplementary information) as potentially affected by the 2010 coastal flood in France. Land cover/use from Corine Land Cover 2012 (Copernicus Land Monitoring Service, 2019b).

\subsubsection{Validation case study: 2013 fluvial flood in Saxony, Germany}

The second case study narrowly overlaps with the German survey data, as they include information from the 2013 fluvial flood. Here, we reproduce losses for a part of the affected area, namely the 
federal state of Saxony. The flood in late spring of 2013 was both intense and widespread, with heavy rainfall (and snowmelt in some mountainous areas) generating in many locations recordbreaking discharge (Schröter et al., 2015). Total losses exceeded 8 billion euro in Germany, some $19 \%$ of which in industry and services (Thieken et al., 2016). Saxon State Ministry of the Environment and Agriculture provided information on the number of claims and total losses in Saxony down to the level of municipalities. Altogether, losses amounted to almost 307 million euro in 2451 companies, including agricultural establishments, but excluding some public services. Due to the availability of detailed water depth simulations, the analysis was limited to four districts (Kreise): Dresden, Meissen, Saxon Switzerland-East Ore Mountains (Sächsische SchweizOsterzgebirge) and North Saxony (Nordsachsen). In those districts, the total losses were 133 million euro (954 claims).

The flood extent and water depths were derived through intersection of recorded floodwater elevations from aerial scanning, carried out by the German Federal Institute of Hydrology during the event (Bundesanstalt für Gewässerkunde, 2015), and a 10-meter digital elevation model from the Federal Agency for Cartography and Geodesy (Bundesamt für Kartographie und Geodäsie, 2015). However, this product is limited to the biggest rivers along which the flood occurred, namely Mulde and Elbe (Figure 5).

Exposure during the 2013 event was estimated firstly by obtaining OSM data for selected districts in Saxony, each of which is an individual NUTS3 region. In contrast to the French case study, no adjustments to OSM data were made, as the share of unknown building occupations was much lower for this study area (9\% altogether). The results of exposure computation per $\mathrm{m}^{2}$ of building footprint area are presented in Supplementary Table S5. OSM was used to identify buildings affected by the flood, again without corrections. The total number of commercial buildings with water depth estimates was 903 , which corresponds to $95 \%$ of the known number of claims in the study area.

Finally, data for the damage model were collected. Information on inundation duration or the use of precautionary measures was again not available. Regional economic data from Eurostat (2020a) provided GVA per capita, which was 18,298-31,135 euro depending on the district (2013 value in 2015 constant price), and GFCF per person employed, which was 11,999 and 12,908 euro in corresponding NUTS2 regions Dresden and Leipzig, respectively. 


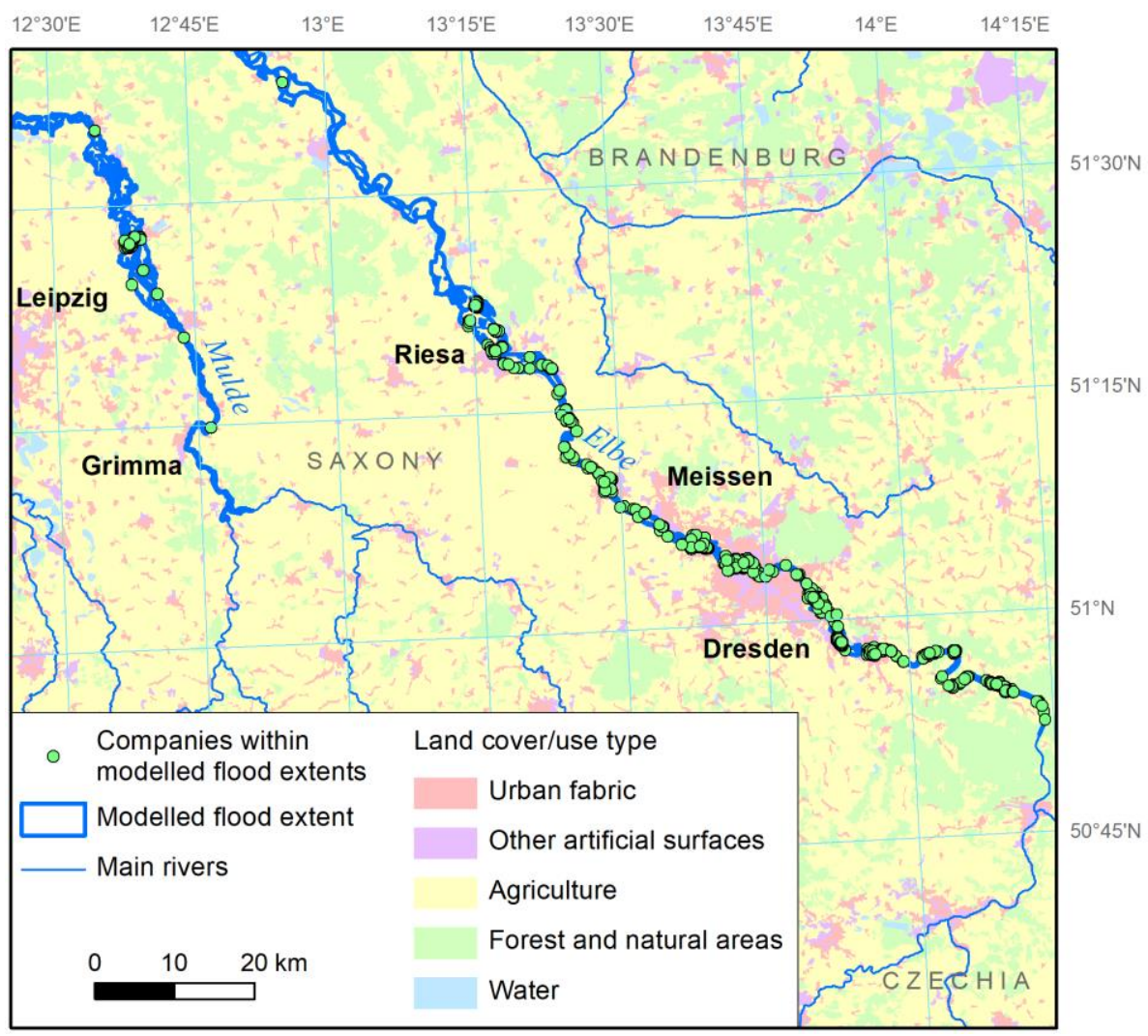

Figure 5. Modelled flood extents and companies identified through OpenStreetMap as potentially affected by the 2013 flood in Saxony. Land cover/use from Corine Land Cover 2012 (Copernicus Land Monitoring Service, 2019b).

\subsubsection{Validation case study: 2014 fluvial flood in Italy}

The final case study reconstructs commercial losses from a flood caused by a dike breach along the river Secchia in the Modena province, northern Italy, on 19 January 2014. The failure of flood defences turned a rather minor rainfall-induced flood into a major event, inundating $52 \mathrm{~km}^{2}$ for two days or more (Orlandini et al., 2015). In contrast to the other case studies, we directly use microdata on commercial flood losses collected after the event rather than aggregated numbers. This information was gathered by local authorities (Emilia-Romagna region, Modena province, Bastiglia, Bomporto and Modena municipalities) with the aim of compensating damages to the business owners. The owners were invited to fill in forms, specifying and demonstrating the amount of damages suffered in terms of building structures, furniture, instruments, stocks, agricultural crops and products and business interruption according to reimbursement criteria set 
by an ad hoc regional-government ordinance. In addition, the addresses and characteristics such as the number of employers before and after the event were recorded. Activities' locations were geocoded by means of an automatic GIS procedure, followed by a careful manual control to avoid errors and uncertainties. The original dataset contains 296 records indicating 15.6 million euro losses to buildings and machinery/equipment. Both categories have shown almost the exact same value (49\% versus $51 \%$ share in combined losses). We note that a similar dataset from the 2014 flood, but for the residential sector, was analyzed previously by Carisi et al. (2018).

Information about flood hazard at each record, i.e. water depth, flow velocity and flood duration, was extracted from the results of a hydrodynamic simulation performed by Carisi et al. (2018) using Telemac-2D model with a one-meter resolution. The model considered topographic discontinuities such as road embankments, artificial and natural channels. The observed outflowing hydrograph of the levee breach was used as boundary condition and the model was calibrated by varying floodplain roughness coefficients. The flood extents were validated using available pictures, videos and reports on the event as well as in situ interviews. This approach was earlier successfully applied for the study area by Vacondio et al. (2016).

Exposure was derived by obtaining OSM buildings for the affected area and then intersecting them with geolocated damage records. Some records referred to the same buildings, hence they were aggregated. Other records, for which no match to OSM buildings was found, were discarded. This was partially caused by lack of precise addresses for some affected companies. The final dataset has 190 records, of which 137 have complete information on building loss and 138 on contents loss. Occupancy of OSM buildings was adjusted according to the type of economic activity indicated by the affected company owners, if such information was provided. In total, there are 49 agricultural, 76 industrial and 65 services companies in the dataset (Figure 6). The value of buildings and machinery/equipment was estimated on the basis of OSM buildings for the Modena province, which forms a NUTS3 region. Data on buildings occupancy was amended with Urban Atlas 2012 to reduce the number of buildings with unknown function. The results of exposure computation per $\mathrm{m}^{2}$ of building footprint area are presented in Supplementary Table S6.

Information on the use of precautionary measures was again not available, but in contrast to the other two case studies inundation duration was obtained from the hydrodynamic simulation. Regional economic data from Eurostat (2020a) provided GVA per capita, which was 35,932 euro 
in the highly industrialized Modena province (2014 value in 2015 constant price). GFCF per person employed was 11,993 euro in the corresponding NUTS2 region Emilia-Romagna.

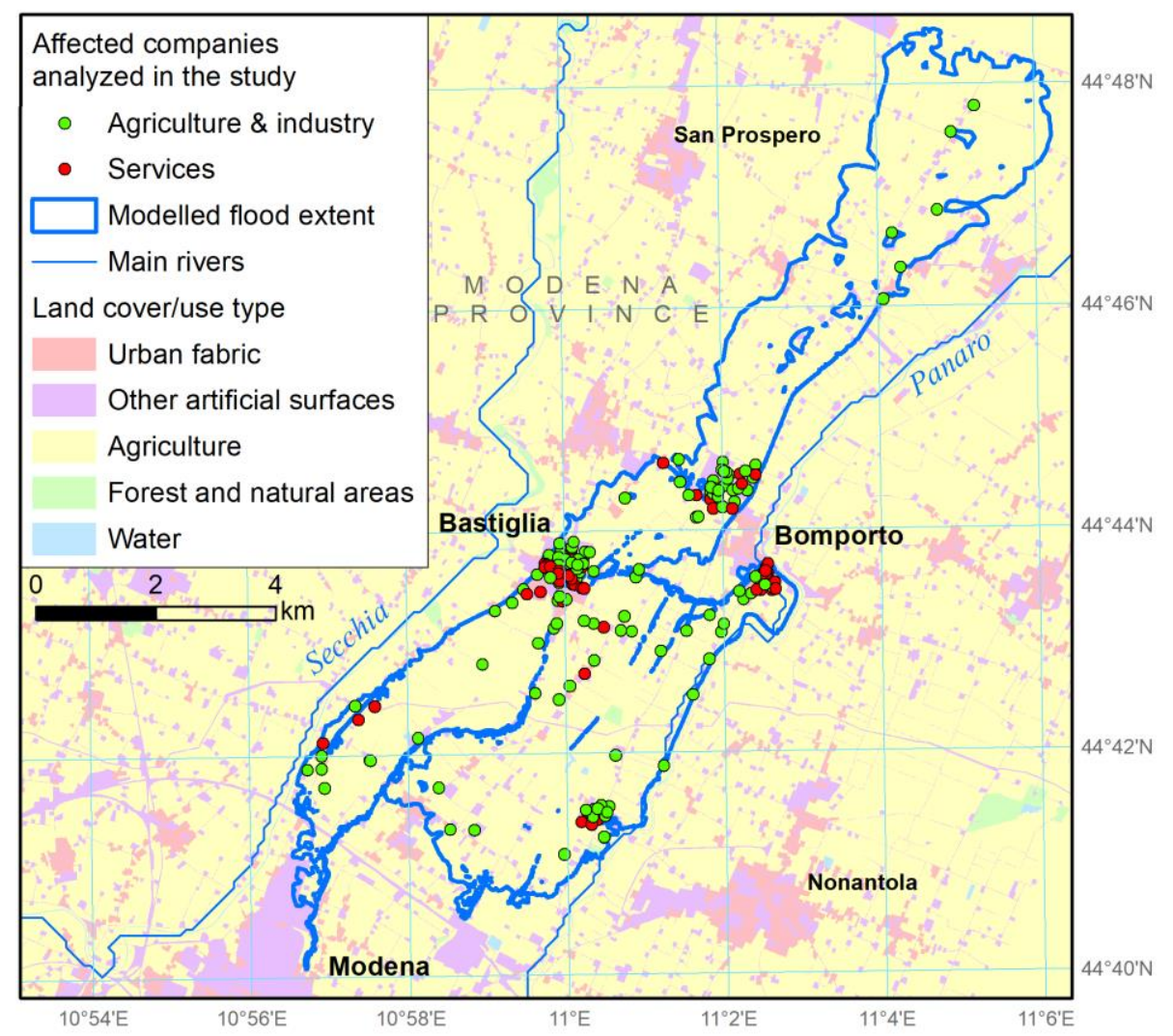

Figure 6. Modelled flood extents and companies affected by the 2014 flood. Land cover/use from Urban Atlas 2012 (Copernicus Land Monitoring Service, 2019a).

\subsubsection{Commercial exposure validation}

Direct validation of commercial exposure estimates is not possible due to the lack of adequate building-level information, but some of the assumptions used here could be tested against alternatives: (1) disaggregating asset stock at the most detailed regional level possible, rather than doing it at the country level; (2) regionalizing asset stock proportionally to GDP rather than according to the number of employees (as was done in Sieg et al., 2017), (3) disaggregating regionalized asset stock proportionally to building footprint area, rather than uniformly per building. For this we use data on fixed assets of enterprises in Poland aggregated at the level of 380 districts (powiat) provided by Statistics Poland (2020). Those administrative units are more 
detailed than NUTS 3 regions, which contain up to nine districts, hence we can test whether our methodology can predict the total value of commercial assets at district level. The dataset does not cover all fixed assets, but only those held by enterprises with 10 employees or more, including certain public health care facilities and cultural institutions. The composition of assets and the breakdown of the services sector also differs somewhat from the one defined for the study, but those uncertainties should not be significant when comparing various approaches to disaggregating the assets to buildings. We use data for 2017, the latest year for which regional economic accounts data are available (Statistics Poland, 2020). The footprint area of buildings by occupation for each district and NUTS region was computed from OSM. The value of assets was first disaggregated proportionately with GVA to three different levels of NUTS regions and then to particular building types, as described in section 2.2. Then, the regional exposure values per $\mathrm{m}^{2}$ were applied to all commercial buildings located in each district. The results were also compared with a disaggregation of assets to buildings at national level to identify the utility of a single countryspecific exposure estimate per building type. Further, it was tested whether it is better to regionalize total asset values proportionally to the number of employees instead of according to GVA (as proposed by Sieg et al., 2019a). Last but not least, disaggregation of assets uniformly to buildings was compared with disaggregation according to building size.

\subsubsection{Performance indices and comparative flood models}

Predictions of relative losses to commercial assets are compared with observations in the German survey data using the following error metrics (Moriasi et al., 2007; Wagenaar et al., 2018):

- Pearson's coefficient of determination $\left(\mathrm{R}^{2}\right)$ was used to measure the degree of collinearity between predicted and observed values, with higher $\mathrm{R}^{2}$ indicating stronger correlation.

- Mean absolute error (MAE) was used to measure the average absolute difference between predicted and observed values, with higher MAE indicating higher error.

- Mean bias error (MBE) was used to measure the average difference between predicted and observed values, with positive $\mathrm{MBE}$ indicating overprediction and negative $\mathrm{MBE}$ indicating underprediction. 
- Symmetric mean absolute percentage error (SMAPE) normalizes MAE by considering the absolute values of predictions and observations, with value close to 0 indicating small error compared to the variability of the phenomena in question.

Appropriate equations are shown in Supplementary Table S7; they are applied to mean (expected) values of the uncertainty distribution of the BN's predictions. The metrics presented in the results are averages of the outcomes of a five-fold cross-validation, i.e. five disjoint sets of one-fifth of the dataset are used in each step to validate the model trained on the remaining four-fifths of the data. Uncertainty ranges are compared with the total amount of observed absolute losses in the relevant categories (economic sector, year of event). As losses from the case studies could only be compared in certain aggregate figures, the mean predictions of the BN model were used, while the uncertainty distribution of losses was used to generate 10,000 possible loss estimates using a Monte Carlo approach. This provided us with uncertainty intervals of the losses. Further, because the number of identified commercial buildings with water depth information was smaller than the reported figures, average losses per building were compared. Estimates of total losses adjusted for undercounting of buildings was also reported, but the difference with observations is the same if average losses are used.

Predictions of losses from the case study events are further compared with alternative exposure and damage models. Comparative asset values were taken from Huizinga et al. (2017), who derived them from a construction costs survey. Replacement cost of buildings were provided separately for the industrial and services sector. Huizinga et al. (2017) didn't provide values for the agricultural sector, hence the figure for industrial buildings was used. The value of machinery and equipment, following the same study, was set as equal building value in the services sector and $150 \%$ of building value in industry (with agriculture). Those estimates will be referred to as "JRC exposure", in opposition to the calculations made according to sections 2.2 and 2.3.2-2.3.4, which will be referred to as "GFZ exposure". JRC exposure estimates for the case studies are presented in Supplementary Table S8.

Six alternative damage models for the commercial sector were collected (Supplementary Table S9). Four are simple univariate damage curves. Two of those include only one curve for all commercial buildings (Hydrotec, 2001; Kok et al., 2005), while another differentiates between industrial/public buildings and other commercial buildings (ICPR, 2001), and the final one gives three different curves for agriculture, industry and services (Huizinga, 2007). Another model, 
MERK (Reese et al., 2003) includes different types of buildings, but not in a particular sector; the average of five curves was used here. However, in contrast to the other damage curves, MERK has separate functions for machinery and equipment. Three curves, one for services and two for industry are available. The two industrial damage curves (representing different building types) were averaged for this application, as they represented different building types. It should be highlighted that MERK was devised specifically for coastal floods.

One multi-variable model was used, based on a selection of the German survey data. FLEMOcs (Kreibich et al., 2010) is a look-up table that distinguishes between losses to buildings and machinery/equipment in four sectors (B-F, G-I, J-N, O-U). This model considers, in the basic version, water depth and number of employees. As the latter variable is not obtainable for the French and Saxon case studies, an average result using three company size assumptions (small, medium, large) is presented. For Italy, the information available from the survey were used where possible, and an average value otherwise. Also, as no function for agriculture is given in FLEMOcs, results were calculated for this sector using damage functions for the industrial sector.

\section{Results}

3.1 Flood damage model performance for the survey data

The predictions of the flood damage model are compared with observations in Figure 7. Uncertainty ranges of modelled flood loss are very large, hence they are presented in the figure using a logarithmic scale. The upper range of the uncertainty distribution $\left(97.5^{\text {th }}\right.$ percentile) is mostly 3-5 times higher than the lower range $\left(2.5^{\text {th }}\right.$ percentile) for events and sectors with a few hundred available data points. The uncertainty is far higher for smaller subsets. The total flood losses are within the $95 \%$ confidence interval in almost all cases. The only exceptions are: losses to buildings during 2002 and 2010 events, and losses to machinery/equipment in the industrial (BF) sector.

The errors are much lower in case of building loss compared to machinery/equipment loss. This is largely because observed relative loss to buildings has shown stronger correlations with various predictors. The data on relative loss to machinery/equipment loss include many instances of 0 (no loss) and 1 (complete loss) values, which are largely absent in the data on relative loss to buildings. Consequently, the uncertainty of the results is higher (Supplementary Figure S4). Predictions of total absolute losses are mostly far worse for machinery/equipment than for 
buildings. This is, however, largely due to a small number of industrial establishments of exceptionally high asset value dominating the results.
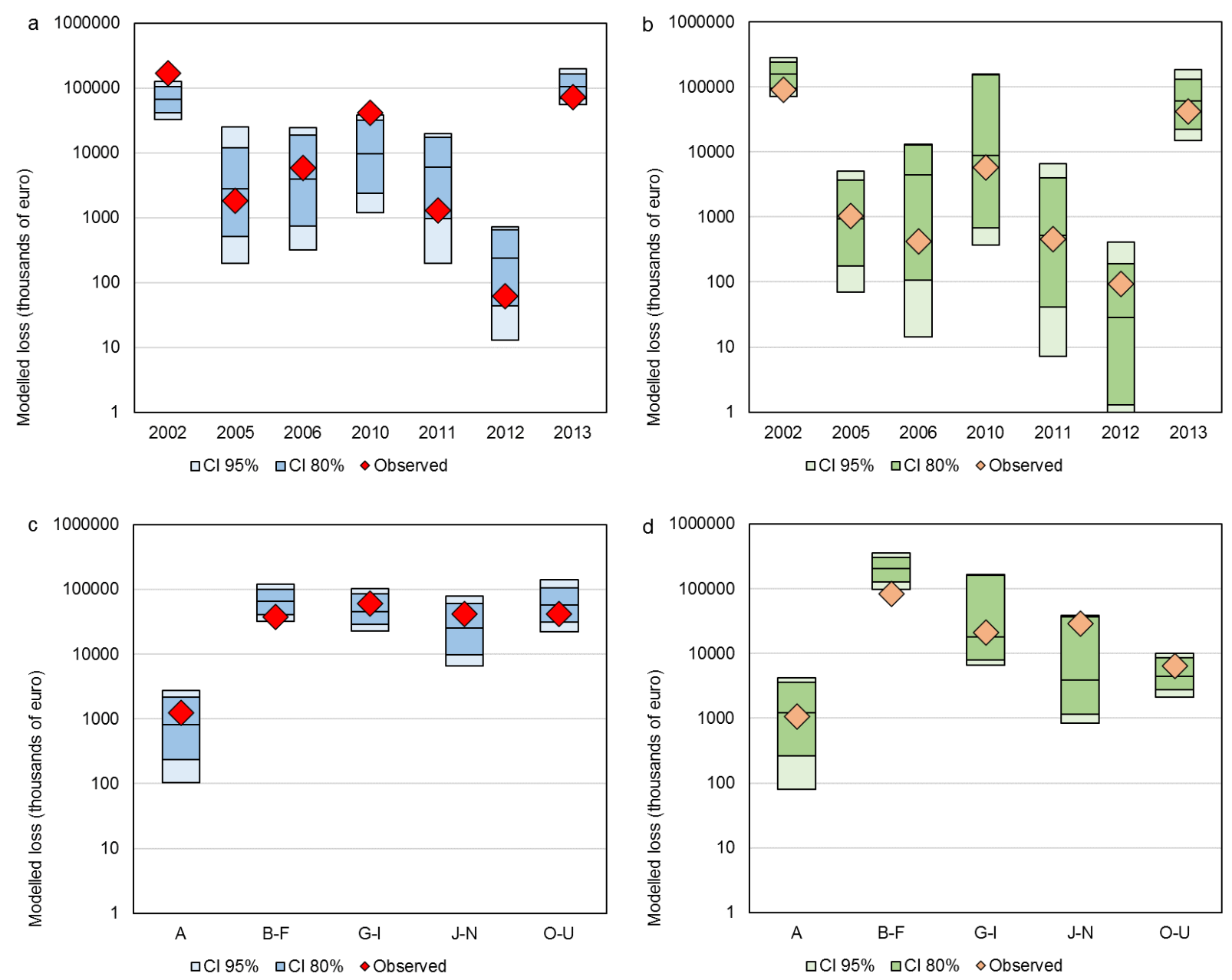

Figure 7. Modelled flood losses in euros with 80 and $95 \%$ confidence intervals per event, using all nodes of the flood damage model, compared with observations: building structure (a) and machinery/equipment (b) by year of event, and building structure (c) and machinery/equipment (d) by economic sector.

Losses at the level of individual companies, obtained from the cross-validation, show a low coefficient of determination $\left(\mathrm{R}^{2}\right)$ below 0.2 (Table 4 ), though it is largely proportional to the variation in observed relative losses, similarly to the magnitude of the mean average error (MAE) 
and mean bias error (MBE). Hence, the error is relatively large with negative bias for the two largest floods in the sample (August 2002 and June 2013), but the symmetric mean absolute percentage error (SMAPE) is lower than for other events, which means that the error is smaller compared to the variation of the relative losses. The datasets for the August 2002 and June 2013 floods contain $77 \%$ of the data points, hence they largely determine the performance of the model. The floods in 2010 are recreated most accurately out of the remaining years. The floods in 2010 are recreated most accurately out of the remaining years. The model's performance is similar across economic activities, with the industrial sector (B-F) narrowly ahead the other sectors. Predictions for agricultural companies are worse, but there are very few data points for this sector (less than $3 \%$ of the total).

Table 4. Validation results of the model by year if the event and sector, using all nodes of the flood damage model. For all companies, the results are an average from a five-fold crossvalidation, while results for the subcategories are from an out-of-sample validation. brloss relative loss to building structure, erloss - relative loss to machinery and equipment.

\begin{tabular}{|c|c|c|c|c|c|c|c|c|}
\hline \multirow{2}{*}{ Item } & \multicolumn{2}{|c|}{$\mathrm{R}^{2}$} & \multicolumn{2}{|c|}{ MAE (\% points) } & \multicolumn{2}{|c|}{ MBE (\% points) } & \multicolumn{2}{|c|}{ SMAPE } \\
\hline & brloss & erloss & brloss & erloss & brloss & erloss & brloss & erloss \\
\hline All companies & 0.12 & 0.11 & 0.16 & 0.29 & 0.00 & -0.04 & 0.52 & 0.52 \\
\hline \multicolumn{9}{|c|}{ Companies by damaging event } \\
\hline 2002 floods & 0.19 & 0.09 & 0.20 & 0.34 & -0.02 & -0.14 & 0.47 & 0.47 \\
\hline 2005 floods & 0.00 & 0.03 & 0.12 & 0.18 & 0.05 & 0.03 & 0.82 & 0.65 \\
\hline 2006 floods & 0.03 & 0.01 & 0.13 & 0.27 & 0.06 & 0.14 & 0.70 & 0.83 \\
\hline 2010 floods & 0.32 & 0.01 & 0.14 & 0.27 & 0.10 & -0.02 & 0.55 & 0.62 \\
\hline 2011 floods & 0.02 & 0.00 & 0.14 & 0.17 & 0.14 & 0.08 & 0.91 & 0.75 \\
\hline 2012 floods & 0.00 & 0.01 & 0.13 & 0.24 & 0.08 & 0.07 & 0.75 & 0.78 \\
\hline 2013 floods & 0.07 & 0.05 & 0.15 & 0.28 & -0.05 & -0.07 & 0.53 & 0.56 \\
\hline \multicolumn{9}{|c|}{ Companies by economic sector } \\
\hline A & 0.07 & 0.10 & 0.19 & 0.23 & 0.01 & 0.08 & 0.66 & 0.59 \\
\hline B-F & 0.14 & 0.14 & 0.16 & 0.26 & -0.03 & 0.03 & 0.50 & 0.49 \\
\hline G-I & 0.07 & 0.11 & 0.17 & 0.32 & -0.03 & -0.14 & 0.53 & 0.54 \\
\hline $\mathrm{J}-\mathrm{N}$ & 0.10 & 0.05 & 0.16 & 0.32 & 0.01 & -0.09 & 0.53 & 0.54 \\
\hline $\mathrm{O}-\mathrm{U}$ & 0.15 & 0.07 & 0.13 & 0.26 & 0.05 & 0.05 & 0.52 & 0.56 \\
\hline
\end{tabular}


3.2 Flood damage model performance for the case studies

The main results of the application of the commercial exposure and damage modelling methods to three case studies (2010 coastal flood in France, 2013 fluvial flood in Saxony, Germany, and 2014 fluvial flood in Italy) are presented in Figure 8, while full results are shown in Supplementary Tables S10-S12. The average losses were slightly overestimated for all events, from $2 \%$ to $19 \%$.

For the 2010 flood in France, the BN model combined with GFZ exposure estimates shows the closest match between average modelled and observed losses per company, with only a $2 \%$ overestimation (uncertainty range from $-24 \%$ to $+35 \%$ ). Good results are also achieved for both economic sectors distinguished, though the losses to agricultural companies were less accurately predicted than those for industry and services. Also, the losses for the two most affected departments were rather less precisely modelled, particularly for Vendée (overestimation by $46 \%$ and large uncertainty bounds). The two departments also sustained higher average losses than the whole area where impacts have occurred, leading to underestimation of losses by the BN.

In contrast, the BN model overestimates average losses for Saxony by 19\%, more than for France or Italy. The 95\% confidence interval is wider, but still within the observed value (-20\% to $+69 \%$ ). The average loss for the districs for which modelled water depths of the event were available shows a closer match (7\% overestimation). However, there is some large variation between districts. In Meissen and North Saxony there is only a 3\% difference between the model and observations, but losses in Saxon Switzerland-East Ore Mountains were underestimated by $40 \%$ and those in the city of Dresden overestimated by $143 \%$. The results for those two districts are the worst in the whole study. This could be partly explained by large differences in our exposure estimates at district level.

Finally, the losses for the Italian companies were overestimated by 12\% (95\% confidence interval $-38 \%$ to $+94 \%$ ). Wide uncertainty ranges are largely caused by a relatively small number of companies analysed in this case study. The predictions for the agricultural and industrial sector were more accurate, but also less confident than for services. Italy is the only case study for which the split by the two main asset types - buildings and machinery/equipment - is available. Losses to building structure were more accurately predicted and with lower uncertainty than those sustained by machinery and equipment. 


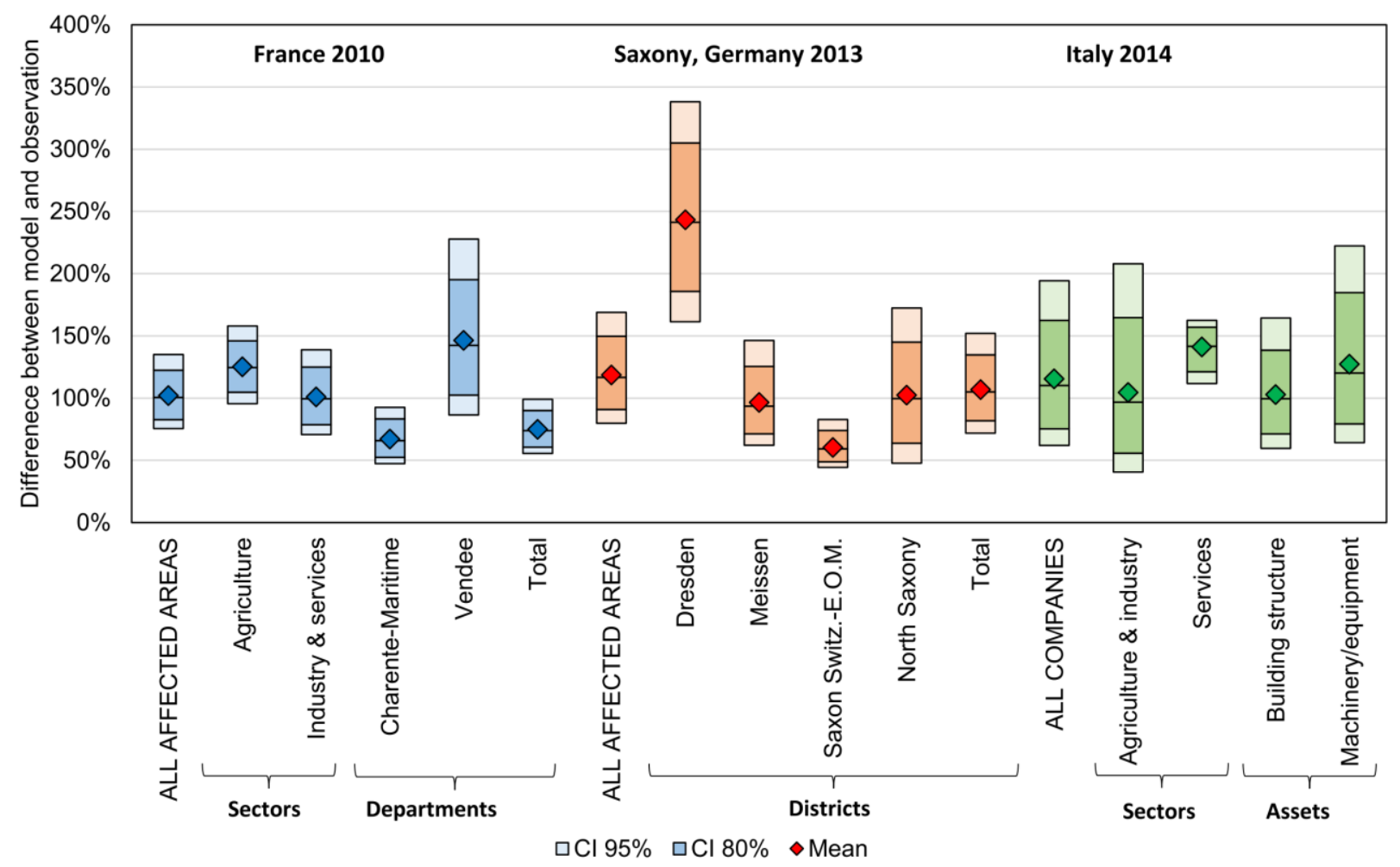

Figure 8. Difference between modelled and observed average losses per company for the case study floods, in various sectoral splits. Bars indicate $80 \%$ and $95 \%$ confidence intervals.

The combination of exposure and damage modelling approaches presented in this study achieved better overall results in estimating flood losses during the floods than alternative approaches, as shown by the main results in Figure 9. The various approaches show similar pattern of overestimation or underestimation: HWS-GIS, JRC, MERK and FLEMOcs show too much damage, while ICPR and SM too little. JRC exposure broadly increase damage estimates compared with GFZ exposure, especially due to vastly higher assumptions on the value of industrial assets and the ratio of machinery/equipment value to buildings in the services sector. The largest differences between different test cases are for MERK and FLEMOcs, mainly due to very steep damage function for machinery and equipment, which also renders them sensitive to exposure estimates in this category of assets. The only instance where the alternative models achieved better results is the combinations of ICPR and SM models with JRC exposure, and only for the Saxony case study. 
Detailed results (Supplementary Tables S13-S15) reveal further interesting comparisons. MERK achieved better estimates for the two departments most affected by the 2010 coastal flood, which can be attributed to the fact that this model was developed specifically for coastal events. However, the results of the Secchia show that the model strongly underestimates building damage while vastly overestimating machinery/equipment loss. Also, the models (including the BN) tend to give too high predictions of losses in the agricultural sector, compared with more accurate predictions for the other sectors in the French case study. This is somewhat not surprising given the lack of separate damage functions for agricultural buildings (in case of the BN model - very small number of data points for this economic activity). Detailed results also indicate one case where the GFZ and JRC exposure estimates were very similar, namely for the city of Dresden. Still, losses were strongly overestimated in both cases. 


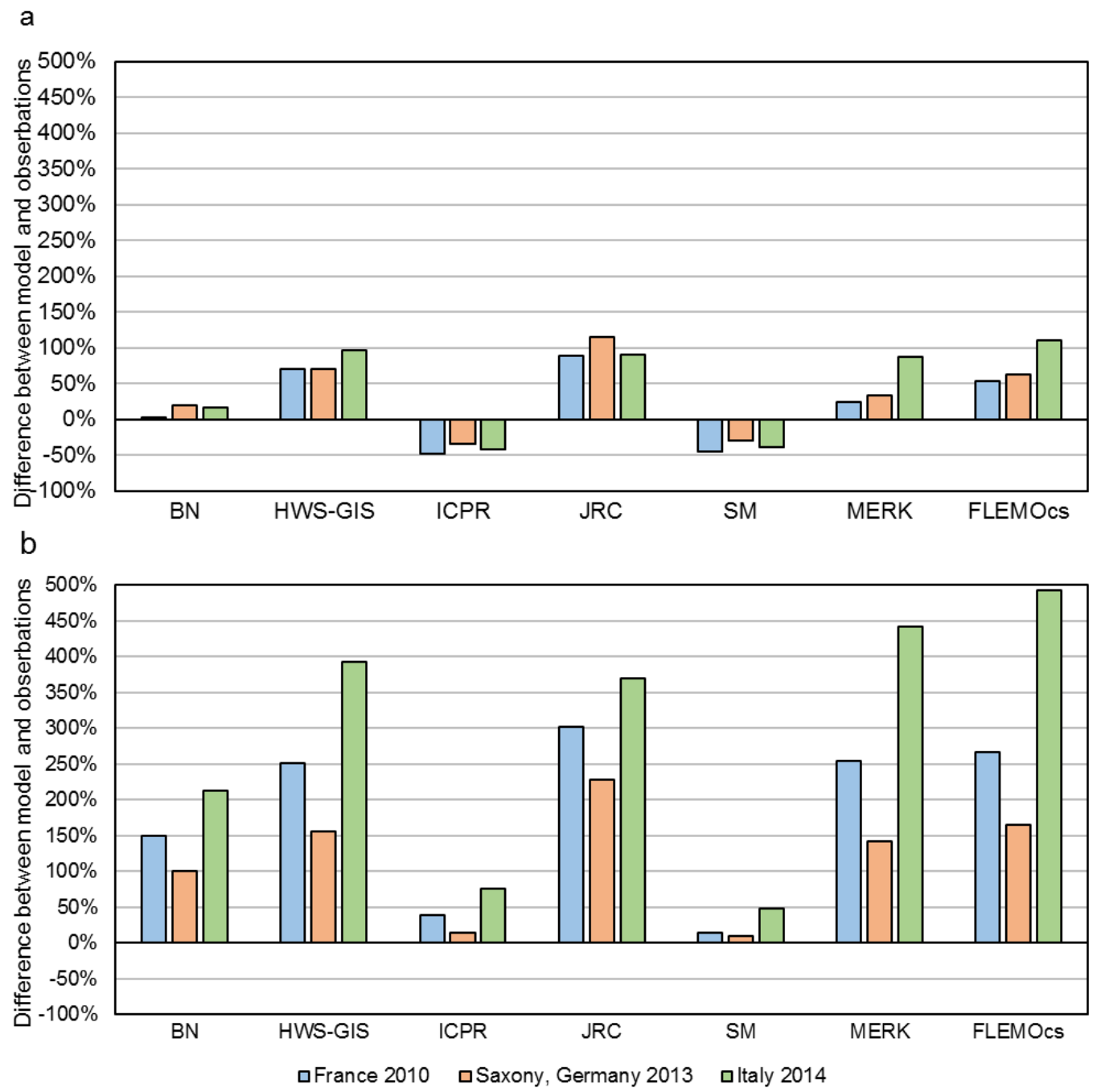

Figure 9. Difference between modelled and observed average losses per company for the case study floods, depending on the choice of exposure estimates ( $\mathrm{a}$ - GFZ exposure, $\mathrm{b}-\mathrm{JRC}$ exposure) and damage model.

\subsection{Commercial exposure case study}

Certain assumptions of computing commercial exposure were tested using data on company assets in districts of Poland in 2017. The results are summarized in Table 5. Our exposure estimates are compared with observations for 374 districts, as six districts also form single NUTS 3 regions. Disaggregation of assets from the national to regional level according to GVA gives better results than using employment as a predictor. Further disaggregation of asset to buildings gives far better 
results when done proportionally to footprint area rather than assigning a uniform value per building. Finally, more detailed regionalization of assets according to GVA is beneficial for the results. Using national-level assets data to generate exposure values per $\mathrm{m}^{2}$ of footprint area gives the least accurate results.

Table 5. Comparison between estimated and reported value of fixed assets in enterprises in 374 districts in Poland in 2017, depending on the disaggregation method.

\begin{tabular}{|l|l|r|r|r|r|}
\hline $\begin{array}{c}\text { Assets disaggregated to regions } \\
\text { proportionally to... }\end{array}$ & $\begin{array}{c}\text { Regionalized assets disaggregated } \\
\text { to OSM buildings proportionally } \\
\text { to... }\end{array}$ & $\begin{array}{c}\mathrm{R}^{2} \\
\text { (mln } \\
\text { PLN) }\end{array}$ & $\begin{array}{c}\text { FAE } \\
\text { (mln } \\
\text { PLN) }\end{array}$ & SMAPE \\
\hline GVA at NUTS 1 level & Footprint area & 0.60 & 2.07 & 0.72 & 0.25 \\
\hline GVA at NUTS 2 level & Footprint area & 0.60 & 1.95 & 0.59 & 0.24 \\
\hline GVA at NUTS 3 level & Footprint area & 0.62 & 1.89 & 0.51 & 0.23 \\
\hline Employment at NUTS 3 level & Footprint area & 0.64 & 1.88 & 0.50 & 0.23 \\
\hline GVA at NUTS 3 level & Uniformly & 0.49 & 2.23 & 0.33 & 0.28 \\
\hline
\end{tabular}

\section{Discussion}

\subsection{Uncertainties and limitations}

Exposure quantification for the commercial sector contains several uncertainties, which are difficult to estimate. The quality and availability of national/regional economic data varies, and the assumption of constant asset to GVA ratio throughout a country's NUTS 3 regions might not hold, e.g. due to different composition of each economic activity sector in a region compared to the national total. On the other hand, the analysis in section 2.3.1 has shown the benefit of this approach compared to alternative methods. Some categories of assets were excluded for the study due to unavailability of exposure data (inventories) or the lack of loss data combined with the need for a different disaggregation method (commercial vehicles, structures other than buildings). The disaggregation itself spreads asset values for a given category of buildings equally per $\mathrm{m}^{2}$ of their footprint area. This disregards the possibility of assets being contained in multiple floors, in contrast to the approach applied to residential buildings in Paprotny et al. (2020). However, commercial buildings often do not follow the concept of floors present in residential or office 
buildings, especially industrial, storage and agricultural buildings. Those constructions are frequently rooms or bays, with some of the mobile assets located on stacks or mezzanines.

The completeness, detail and accuracy of OpenStreetMap (OSM) varies between locations, both in terms of building footprints and functions. In some countries, government-run databases are integrated into the OSM providing virtually complete information on buildings and their occupation (e.g. in the Netherlands and Germany). In others, even the availability of building footprints is limited (e.g. in Greece and Spain). This could impact severely the accuracy of the disaggregation. In the French and Italian study areas, the building footprints are rather complete, but there is a large share of buildings with unknown or imprecisely-defined occupation. The data for Saxony provides both high level of detail and completeness. Additionally, OSM is constantly updated, with more than 100,000 buildings added daily (Schorlemmer et al., 2017). Data on building occupancy can be further amended using external sources, e.g. Urban Atlas and Corine Land Cover as shown in the case studies.

Some uncertainty is related to the German survey data. The dataset contains the respondents' recollections of the flood event, which had occurred between 6 and 50 months prior to the survey (Thieken et al., 2017). Therefore, there might be inaccuracies in the data related to the hazard component (water depth, inundation duration), the economic situation of the company or the use of precautionary measures. In particular, occurrences of relative losses equal to 0 and 1 are more frequent than in the corresponding German survey data on residential losses. Another possible concern is the transferability of German data into other areas, but this is addressed by the French and Italian case studies presented here.

The commercial damage model uses only continuous variables. This could be addressed by applying a hybrid continuous-discrete model, but in practice the only discrete variable that would be easily available for application of the model is the economic activity sector. Sieg et al. (2017) made separate Random Forest models for four sectors (excluding agriculture due to a small number of data points), hence a similar approach could be applied by making different models for industry or services. However, the pool of survey data is small in each of the five sectors distinguished, hence we opted to use a different approach and try to capture the dependencies between variables relevant for all companies.

On a more general level, Bayesian Networks were primarily used due to the explicit representation of the dependency structure and their ability to operate with missing data. Two 
nodes of the damage model were not used in the studies (inundation duration and the precautionary measures index), except for the Italian case study for which inundation duration was available. This variable is not obtainable when a static flood approach is used, but can be derived from dynamic models. Precautionary measures index in not directly obtainable locally unless similar survey data are collected, but was nonetheless kept in the model as it enables providing model results under different precaution scenarios. Also, certain types of precautionary actions might be also mandatory by law in particular areas, thus providing some information for the model.

The damage model has shown promising results for the case studies, though in same categories the performance was less good. For instance, losses for two French departments that were most affected covered by the flood hazard data were underestimated (by 25\%, uncertainty range from 0 to $44 \%$ ). Consequently, the inaccuracy can be explained by limitations of the hazard and exposure data. The reanalysis of the 2010 flood matches the observed flood extent well, but misses in particular many populated places. Together with limitations of OSM data, many commercial establishments were missed. Some difference between modelled and observed losses could be caused by mismatch in capturing the structure of companies by activity, as e.g. average loss sustained by agricultural companies was almost three times lower than for companies in industry and services. Here, OSM data is very complete and the flood mask closely matching the actual flood extents, therefore the affected buildings were identified with high accuracy. However, exposure is rather strongly overestimated for the city of Dresden, and the resulting losses are too high. For Italy, the main source of uncertainty is the rather small number of companies in the compensation claim data.

In this study, estimates of the damage model was compared only for the three case studies, because a comparison with the German survey data would give the BN model an advantage over the other methods which were not trained with the same dataset. Only FLEMOcs used the same dataset to some extent, as it was built on survey data for flood events that had occurred between 2002 and 2006. Still, such a comparison can provide some additional insights (Supplementary Tables S16 and S17). Despite low correlation between observations and the predictions of the BN model $\left(\mathrm{R}^{2}=0.10-0.12\right)$, the other damage functions which distinguish relative losses to buildings and machinery/equipment achieved even lower performance $\left(\mathrm{R}^{2}=0.01-0.05\right)$. Concentration of the results around the average has been a common problem among multivariate models (Amadio et al., 2019; Carisi et al., 2018; Dottori et al., 2016), stemming from relatively few observations of 
very high relative losses. Considering all available absolute loss estimates in the survey data, ICPR and SM models achieved a better match between modelled and observed data than the BN model. However, the performance of all models varies substantially between economic activities and flood events, with ICPR and SM having the best estimates for industry and the 2002 floods, while MERK and the BN models performing best for the 2013 event and certain types of companies. The BN model also had better quality regarding building losses than the other models, though ICPR was more accurate regarding losses to machinery and equipment. Interestingly, FLEMOcs overestimated losses substantially in most categories, despite using German survey data.

\subsection{Future outlook}

We can also remark on the aspect of land use in flood zones, changes of which are an important driver of flood losses (Boudou et al., 2016; Paprotny et al., 2018a; 2018b). The distribution of modelled flood losses (like in Supplementary Fig. S5-S7) could inform on the potential damages that could be sustained for planned construction (Apollonio et al., 2016, Bathrellos et al. 2012, 2016). Our exposure estimation method combined with the BN model enables making comparative analyses of different adaptation and mitigation approaches related to land-use planning, such as asset relocation, building design adaptation (e.g. increasing ground floor height) or restrictions on certain activities (particularly those with the highest exposure).

The flood loss modelling methods presented here in will be analysed further within an EIT Climate-KIC Demonstrator project "SaferPLACES". There are three case studies in the project, namely Cologne (Germany), Pamplona (Spain) and Rimini (Italy). In each city, an interactive web tool for flood risk assessment will be implemented, utilizing only open data as inputs. Local validation will be carried out using primarily government or insurance data, either on individual building level or at some level of aggregation. The precautionary measures index included in the damage model can be used to incorporate flood mitigation scenarios in the work. Otherwise, mitigation would be implemented as through appropriate adjustment of hazard and exposure data.

\section{Conclusions}

In this paper we used post-disaster flood survey data for German companies to create a new multivariable damage model for commercial assets. The study covered commercial buildings as well as machinery and equipment, but excluded infrastructure, vehicles, and inventories. The resulting 
non-parametric Bayesian Network $(\mathrm{BN})$ with seven variables includes two variables of interest (relative loss to building structure, and separately to machinery/equipment) and five explanatory variables related to flood hazard (water depth, inundation duration), exposure (regional gross value added and gross fixed capital formation) and vulnerability (use of precautionary measures). The model is accompanied by a method of estimating building-level exposure using openly-available data. It is applicable wherever building data from the global crowd-sourced OpenStreetMap dataset is available together with some basic economic data at regional or national level. Though microscale validation of the method was not possible, an analysis using local data on company assets in Poland indicated reasonable performance in predicting aggregated asset values.

The performance of the $\mathrm{BN}$ model in terms of estimating relative losses compared to observations varies between economic activity sector and year of flood events. The model has shown rather good accuracy of predictions of building losses, but overestimated machinery/equipment loss for the surveyed German companies. However, many sectors/events contained very few data points, and overall the large uncertainty in the input data result in very scattered predictions; the same was the case when testing comparable damage models. Case studies of past coastal and fluvial floods in France (2010), Saxony (Germany, 2013) and Italy (2014) were used to test the model in different environments, independently validating the model and providing a fair comparison with other damage models. The BN model combined with our exposure estimates was the most accurate in estimating average observed losses per affected company for the whole area inundated by the coastal flood in France in 2010, but underestimated losses for the two most affected regions. In case of the fluvial floods in Saxony and Italy, the losses were overestimated, but less than in case of most other models. Other models mostly overestimated losses from the events. Alternative exposure valuation from JRC further reduced the accuracy of the simulation. At least some uncertainties can be attributed to the limitations of available data on observed losses, flood intensity and buildings.

In summation, we have confirmed our hypothesis that using a Bayesian Network approach combined with novel use of openly-available spatial and statistical data did improve commercial flood loss estimation in European case studies. The methods introduced here will be further tested and evaluated in European case studies. Together with residential exposure and damage modelling approaches it is the most comprehensive tool for probabilistic flood loss assessments in Europe achieved so far. Importantly, all can be applied using only open or openly-available data. 


\section{Acknowledgments}

This work was supported by Climate-KIC through project "SAFERPLACES - Improved assessment of pluvial, fluvial and coastal flood hazards and risks in European cities as a mean to build safer and resilient communities", Task ID TC2018B_4.7.3-SAFERPL_P430-1A KAVA2 4.7.3. Further funding was received funding from the European Union's Horizon 2020 research and innovation programme under grant agreement no. 730381. The post-disaster surveys were carried out by a joint venture between the German Research Centre for Geosciences GFZ, the University of Potsdam and the Deutsche Rueckversicherung AG, Duesseldorf. The surveys were further supported by the German Ministry of Education and Research (BMBF) through projects DFNK 01SFR9969/5 and "Hochwasser 2013', (13N13017). Most of the German flood loss data are available via the German flood damage database HOWAS21 (http://howas21.gfzpotsdam.de/howas21/). The authors would like to thank: Xavier Bertin for sharing data from his coastal flood modelling work on the 2010 event; Fabio Brill for sharing data from his river flood modelling work on the 2013 event; Lukas Schoppa for technical support with the German survey data; Danijel Schorlemmer and Thomas Beutin for adapting OSM data to the GEM building taxonomy and technical discussions. Bayesian Network code is available upon reasonable request from Oswaldo Morales-Nápoles until it becomes publicly available.

\section{References}

Amadio, M., Scorzini, A. R., Carisi, F., Essenfelder, A. H., Domeneghetti, A., Mysiak, J., \& Castellarin, A. (2019). Testing empirical and synthetic flood damage models: the case of Italy. Nat. Hazards Earth Syst. Sci., 19, 661-678. https://doi.org/10.5194/nhess-19-6612019

Apel, H., Aronica, G. T., Kreibich, H., \& Thieken, A. H. (2009). Flood risk analyses-how detailed do we need to be?. Nat. Hazards, 49(1), 79-98. https://doi.org/10.1007/s11069008-9277-8

Apollonio, C., Balacco, G., Novelli, A., Tarantino, E., Piccinni, A. F. (2016). Land Use Change Impact on Flooding Areas: The Case Study of Cervaro Basin (Italy). Sustainability, 8, 996. 
Post print of a paper in Science of the Total Environment, DOI 10.1016/j.scitotenv.2020.140011

Axer, T., Bistry, T., Klawa, M., Müller, M., \& Süßer, M. (2012). Sturmdokumentation 2011 Deutschland. Düsseldorf, Germany: Deutsche Rückversicherung. Retrieved from https://www.deutscherueck.de/fileadmin/user_upload/Sturmdoku_2011_WEB.pdf (last accessed 30.10.2019).

Bathrellos, G. D., Gaki-Papanastassiou, K., Skilodimou, H. D., Papanastassiou, D., Chousianitis, K. G. (2012). Potential suitability for urban planning and industry development by using natural hazard maps and geological - geomorphological parameters. Environ. Earth Sci., 66(2), 537-548.

Bathrellos, G. D., Karymbalis, E., Skilodimou, H. D., Gaki-Papanastassiou, K., Baltas, E. A. (2016). Urban flood hazard assessment in the basin of Athens Metropolitan city, Greece. Environ. Earth Sci., 75(4), 319.

Bathrellos, G. D., Skilodimou, H. D., Chousianitis, K., Youssef, A. M., \& Pradhan, B. (2017). Suitability estimation for urban development using multi-hazard assessment map. Sci. Total Environ., 575, 119-134.

Bayerisches Landesamt für Umwelt (2007). Gewässerkundlicher Bericht Hochwasser August 2005. Augsburg, Germany: BLfU. Retrieved from https://www.lfu.bayern.de/wasser/hw_ereignisse/2005/doc/hw200508_endbericht.pdf (last accessed 30.10.2019).

Bertin, X., Bruneau, N., Breilh, J.-F., Fortunato, A. B., \& Karpytchev, M. (2012). Importance of wave age and resonance in storm surges: the case Xynthia, Bay of Biscay. Ocean Modell., 42, 16-30. https://doi.org/10.1016/j.ocemod.2011.11.001

Bertin, X., Li, K., Roland, A., Zhang, Y. J., Breilh, J. F., \& Chaumillon, E. (2014). A modelingbased analysis of the flooding associated with Xynthia, central Bay of Biscay. Coastal Eng., 94, 80-89. https://doi.org/10.1016/j.coastaleng.2014.08.013

Boudou, M., Danière, B., \& Lang, M. (2016). Assessing changes in urban flood vulnerability through mapping land use from historical information. Hydrol. Earth Syst. Sci., 20, 161173. https://doi.org/10.5194/hess-20-161-2016 
Post print of a paper in Science of the Total Environment, DOI 10.1016/j.scitotenv.2020.140011

Brémond, P., Grelot, F., \& Agenais, A.-L. (2013). Review Article: Economic evaluation of flood damage to agriculture - review and analysis of existing methods, Nat. Hazards Earth Syst. Sci., 13, 2493-2512, https://doi.org/10.5194/nhess-13-2493-2013

Brzev, S., Scawthorn, C., Charleson, A. W., Allen, L., Greene, M., Jaiswal, K., \& Silva, V. (2013). GEM Building Taxonomy Version 2.0. GEM Technical Report 2013-02. Pavia, Italy: GEM Foundation. https://doi.org/10.13117/GEM.EXP-MOD.TR2013.02

Bundesamt für Kartographie und Geodäsie (2015). Digitales Geländemodell Gitterweite 10 m. Retrieved from https://sg.geodatenzentrum.de/web_public/gdz/dokumentation/deu/dgm10.pdf (last accessed 19.12.2019).

Bundesanstalt für Gewässerkunde (2006). Das Hochwasser der Elbe im Frühjahr 2006 (BfG1514). Koblenz, Germany: BfG. Retrieved from http://undine.bafg.de/elbe/extremereignisse/img/BfG_Bericht_HW2006.pdf (last accessed 30.10.2019).

Bundesanstalt für Gewässerkunde (2015). Produktblatt: Flugzeuggestützte Erfassung der Hochwasserereignisse an Elbe und Donau, 2013. Koblenz, Germany: Referat Geodäsie, Geotopographie.

Carisi, F., Schröter, K., Domeneghetti, A., Kreibich, H., \& Castellarin, A. (2018). Development and assessment of uni- and multivariable flood loss models for Emilia-Romagna (Italy). Nat. Hazards Earth Syst. Sci., 18, 2057-2079. https://doi.org/10.5194/nhess-18-20572018

Chatterton, J., Viavattene, C., Morris, J., Penning-Rowsell, E., Tapsell, S. (2010). The costs of the summer 2007 floods in England. Bristol, UK: Environment Agency. Retrieved from https://assets.publishing.service.gov.uk/government/uploads/system/uploads/attachment_ data/file/291190/scho1109brja-e-e.pdf (last accessed 25.10.2019).

Copernicus Land Monitoring Service (2019a). Urban Atlas. Retrieved from https://land.copernicus.eu/local/urban-atlas (last accessed 8.11.2019).

Copernicus Land Monitoring Service (2019b). CORINE Land Cover. Retrieved from https://land.copernicus.eu/pan-european/corine-land-cover (last accessed 8.11.2019). 
Post print of a paper in Science of the Total Environment, DOI 10.1016/j.scitotenv.2020.140011

De Moel, H., \& Aerts, J. C. J. H. (2011). Effect of uncertainty in land use, damage models and inundation depth on flood damage estimates. Nat. Hazards, 58(1), 407-425. https://doi.org/10.1007/s11069-010-9675-6

Dottori, F., Figueiredo, R., Martina, M. L. V., Molinari, D., \& Scorzini, A. R. (2016). INSYDE: a synthetic, probabilistic flood damage model based on explicit cost analysis. Nat. Hazards Earth Syst. Sci., 16, 2577-2591. https://doi.org/10.5194/nhess-16-2577-2016, 2016.

Engel, H. (2004). The flood event 2002 in the Elbe River basin: Causes of the flood, its course, statistical assessment and flood damages. La Houille Blanche, (6), 33-36.

Eurostat (2013). European system of accounts ESA 2010. Luxembourg: Publications Office of the European Union.

Eurostat (2020a). Database. Retrieved from https://ec.europa.eu/eurostat/data/database (last accessed 29.1.2020).

Eurostat (2020b). GISCO: geographical information and maps. Retrieved from https://ec.europa.eu/eurostat/web/gisco/overview (last accessed 29.1.2020).

Fédération Française de l'Assurance (2017). L'assurance des catastrophes naturelles en 2016. Retrieved from https://www.mrn.asso.fr/wp-content/uploads/2017/01/2017-chiffreassurance-des-catastrophes_naturelles_2016.pdf (last accessed 25.10.2019).

FFSA / GEMA (2011). La tempête Xynthia du 28 février 2010 - Bilan chiffré au 31 décembre 2010. Retrieved from https://www.mrn.asso.fr/wp-content/uploads/2018/01/2010-bilantempete-xynthia-2010-ffsa-gema.pdf (last accessed 25.10.2019).

Gerl, T., Bochow, M., \&Kreibich. H. (2014). Flood Damage Modeling on the Basis of Urban Structure Mapping Using High-Resolution Remote Sensing Data. Water, 6(8), 23672393. https://doi.org/10.3390/w6082367

Gerl, T., Kreibich, H., Franco, G., Marechal, D., Schröter, K. (2016). A Review of Flood Loss Models as Basis for Harmonization and Benchmarking. PLoS ONE, 11(7), e0159791. https://doi.org/10.1371/journal.pone.0159791 
Post print of a paper in Science of the Total Environment, DOI 10.1016/j.scitotenv.2020.140011

Hanea, A. M., Kurowicka, D., \& Cooke, R. M. (2006). Hybrid Method for Quantifying and Analyzing Bayesian Belief Nets. Qual. Reliab. Eng. Int., 22, 709-729. https://doi.org/10.1002/qre.808

Hanea, A., Morales Nápoles, O., \& Ababei, D. (2015). Non-parametric Bayesian networks: Improving theory and reviewing applications. Reliab. Eng. Syst. Saf., 144, 265-284. https://doi.org/10.1016/j.ress.2015.07.027

Huizinga, H. J. (2007). Flood damage functions for EU member states (PR1278.10). Lelystad, the Netherlands: HKV Consultants.

Huizinga, J., de Moel, H., \& Szewczyk, W. (2017). Global flood depth-damage functions. Methodology and the database with guidelines (EUR 28552 EN). Retrieved from https://doi.org/10.2760/16510 (last accessed 28.10.2019).

Hydrotec (2001). Hochwasser-Aktionsplan Angerbach. Teil I: Berichte und Anlagen. Aachen, Germany: Staatlichen Umweltamtes Düsseldorf.

ICPR (2001). Atlas on the risk of flooding and potential damage due to extreme floods of the Rhine. Koblenz, Germany: International Commission for the Protection of the Rhine (ICPR).

INSEE (2018). Capital fixe et consommation de capital fixe en 2017. Retrieved from https://www.insee.fr/fr/statistiques/3547407?sommaire=3547646 (last accessed 8.11.2019).

Jato-Espino, D., Lobo, A., \& Ascorbe-Salcedo, A. (2019). Urban flood risk mapping using an optimised additive weighting methodology based on open data. J. Flood Risk Manage., 12, e12533. https://doi.org/10.1111/jfr3.12533

Jongman, B., Kreibich, H., Apel, H., Barredo, J. I., Bates, P. D., Feyen, L., Gericke, A., Neal, J., Aerts, J. C. J. H., \& Ward, P. J. (2012). Comparative flood damage model assessment: towards a European approach. Nat. Hazards Earth Syst. Sci., 12, 3733-3752. https://doi.org/10.5194/nhess-12-3733-2012

Kazakis, N., Kougias, I., Patsialis, T. (2015). Assessment of flood hazard areas at a regional scale using an index-based approach and Analytical Hierarchy Process: Application in Rhodope-Evros region, Greece. Sci. Total Environ., 538: 555-563. 
Post print of a paper in Science of the Total Environment, DOI 10.1016/j.scitotenv.2020.140011

Keller, L., Zischg, A. P., Mosimann, M., Rossler, O., Weingartner, R., \& Martius, O. (2019). Large ensemble flood loss modelling and uncertainty assessment for future climate conditions for a Swiss pre-alpine catchment. Sci. Total Environ., 693, 133400. https://doi.org/10.1016/j.scitotenv.2019.07.206

Kellermann, P., Schröter, K., Thieken, A. H., Haubrock, S.-N., \& Kreibich, H. (2020). The object-specific flood damage database HOWAS21. Nat. Hazards Earth Syst. Sci. Discuss., in review, https://doi.org/10.5194/nhess-2019-420

Kelman, O., \& Spence, R. (2004). An overview of flood actions on buildings. Eng. Geol., 73, 297-309. https://doi.org/10.1016/j.enggeo.2004.01.010

Kok, M., Huizinga, H., Vrouwenvelder, A., \& Barendregt, A. (2005). Standaardmethode2004 Schade en Slachtoffers als gevolg van overstromingen (DWW-2005-005). RWS Dienst Weg- en Waterbouwkunde. Retrieved from https://library.wur.nl/ebooks/hydrotheek/1874298.pdf (last accessed 28.10.2019).

Kolen, B., Slomp, R., \& Jonkman, S. N. (2013). The impacts of storm Xynthia February 27-28, 2010 in France: lessons for flood risk management. J. Flood Risk Manage., 6(3), 261278. https://doi.org/10.1111/jfr3.12011

Kreibich, H., Müller, M., Thieken, A. H., \& Merz, B. (2007). Flood precaution of companies and their ability to cope with the flood in August 2002 in Saxony, Germany. Water Resour. Res., 43(3), W03408. https://doi.org/10.1029/2005WR004691

Kreibich, H. Seifert, I., Merz, B., \& Thieken, A. H. (2010). Development of FLEMOcs - a new model for the estimation of flood losses in the commercial sector. Hydrol. Sci. J., 55(8), 1302-1314. https://doi.org/10.1080/02626667.2010.529815

Kurowicka, D., \& Cooke, R. (2006). Uncertainty analysis with high dimensional dependence modelling. Chichester, UK: John Wiley.

Merz, B., Kreibich, H., \& Lall, U. (2013). Multi-variate flood damage assessment: a tree-based data-mining approach. Nat. Hazards Earth Syst. Sci., 13, 53-64. https://doi.org/10.5194/nhess-13-53-2013

Morales-Nápoles, O., Hanea, A. M., \& Worm, D. T. H. (2014). Experimental results about the assessments of conditional rank correlations by experts: example with air pollution 
Post print of a paper in Science of the Total Environment, DOI 10.1016/j.scitotenv.2020.140011

estimates. In: Steenbergen RDJM, Van Gelder PHAJM, Miraglia S, Vrouwenvelder ACWM, editors. Safety, Reliability and Risk Analysis: Beyond the Horizon, London: Taylor \& Francis, 1359-1366.

OpenStreetMap (2020). OpenStreetMap. Retrieved from https://www.openstreetmap.org/ (last accessed 20.2.2020).

Orlandini, S., Moretti, G., \& Albertson, J. D. (2015). Evidence of an emerging levee failure mechanism causing disastrous floods in Italy. Water Resour. Res., 51, 7995-8011. https://doi.org/10.1002/2015WR017426

Paprotny, D., Kreibich, H., Morales-Nápoles, O., Terefenko, P., \& Schröter, K. (2020) Estimating exposure of residential assets to natural hazards in Europe using open data. Nat. Hazards Earth Syst. Sci., 20, 323-343, https://doi.org/10.5194/nhess-20-323-2020

Paprotny, D., Morales-Nápoles, O., \& Jonkman, S. N. (2018a). HANZE: a pan-European database of exposure to natural hazards and damaging historical floods since 1870. Earth Syst. Sci. Data, 10, 565-581. https://doi.org/10.5194/essd-10-565-2018

Paprotny D., Sebastian A., Morales Nápoles O., \& Jonkman S. N. (2018b). Trends in flood losses in Europe over the past 150 years. Nat. Commun., 9, 1985. https://doi.org/10.1038/s41467-018-04253-1.

Penning-Rowsell, E., Priest, S., Parker, D., Morris, J., Tunstall, S., Viavattene, C., Chatterton, J., \& Owen, D. (2013). Flood and Coastal Erosion Risk Management: a Manual for Economic Appraisal. London: Routledge.

Polnisch-deutsch-tschechische Expertengruppe (2010). Gemeinsamer polnisch-deutschtschechischer Bericht zum Hochwasser vom 07. bis 10. August 2010 an der Lausitzer Neiße als Bestandteil der vorläufigen. Wrocław/Dresden/Prague. Retrieved from https://docplayer.org/39152711-Gemeinsamer-polnisch-deutsch-tschechischer-berichtzum-hochwasser-vom-07-bis-10-august-2010-an-der-lausitzer-neisse-als-bestandteil-dervorlaeufigen.html (last accessed 30.10.2019).

Reese, S., Markau, H.-J., \& Sterr, H. (2003). MERK - Mikroskalige Evaluation der Risiken in überflutungsgefährdeten Küstenniederungen. Büsum, Germany: Forschungs- und Technologiezentrum Westküste. Retrieved from 
Post print of a paper in Science of the Total Environment, DOI 10.1016/j.scitotenv.2020.140011

http://citeseerx.ist.psu.edu/viewdoc/download?doi=10.1.1.463.1390\&rep=rep1\&type=pdf (last accessed 28.10.2019).

Roland, A., Zhang, Y. J., Wang, H. V., Meng, Y., Teng, Y.-C., Maderich, V., Brovchenko, I., Dutour-Sikiric, M., \& Zanke, U. (2012). A fully coupled 3D wave-current interaction model on unstructured grids. J. Geophys. Res., 117, C00J33.

Schorlemmer, D., Beutin, T., Hirata, N., Hao, K., Wyss, M., Cotton, F., \& Prehn, K. (2017). Global Dynamic Exposure and the OpenBuildingMap - Communicating Risk and Involving Communities. Geophys. Res. Abstr., 19, EGU2017-7060.

Schröter, K., Kreibich, H., Vogel, K., Riggelsen, C., Scherbaum, F., \& Merz, B. (2014). How useful are complex flood damage models?. Water Resour. Res., 50(4), 3378-3395. https://doi.org/10.1002/2013WR014396

Schröter, K., Kunz, M., Elmer, F., Mühr, B., \& Merz, B. (2015). What made the June 2013 flood in Germany an exceptional event? A hydro-meteorological evaluation. Hydrol. Earth Syst. Sci., 19, 309-327. https://doi.org/10.5194/hess-19-309-2015

Schröter, K., Lüdtke, S., Redweik, R., Meier, J., Bochow, M., Ross, L., Nagel, C., \& Kreibich, H. (2018). Flood Loss Estimation Using 3D City Models and Remote Sensing Data. Environ. Modell. Software, 105, 118-131. https://doi.org/10.1016/j.envsoft.2018.03.032

Seifert, I., Kreibich, H., Merz, B., \& Thieken, A. H. (2010a). Application and validation of FLEMOcs - a flood-loss estimation model for the commercial sector. Hydrol. Sci. J., 55(8), 1315-1324. https://doi.org/10.1080/02626667.2010.536440

Seifert, I., Thieken, A.H., Merz, M., Borst, D., \& Werner, U. (2010b). Estimation of industrial and commercial asset values for hazard risk assessment. Nat. Hazards, 52(2), 453-479. https://doi.org/10.1007/s11069-009-9389-9

Sieg, T., Schinko, T., Vogel, K., Mechler, R., Merz, B., \& Kreibich, H. (2019a) Integrated assessment of short-term direct and indirect economic flood impacts including uncertainty quantification. PLoS ONE, 14(4), e0212932. https://doi.org/10.1371/journal.pone.0212932 
Post print of a paper in Science of the Total Environment, DOI 10.1016/j.scitotenv.2020.140011

Sieg, T., Vogel, K., Merz, B., \& Kreibich, H. (2017). Tree-based flood damage modeling of companies: Damage processes and model performance. Water Resour. Res., 53(7), 6050 6068. https://doi.org/10.1002/2017WR020784.

Sieg, T., Vogel, K., Merz, B., \& Kreibich, H. (2019b). Seamless estimation of hydrometeorological risk across spatial scales. Earth's Future, 7(5), 574-581. https://doi.org/10.1029/2018EF001122

Statistics Poland (2020). Local Data Bank. Retrieved from https://bdl.stat.gov.pl/BDL/start (last accessed 20.2.2020).

Statistisches Bundesamt (2019). GENESIS-Online Datenbank. Retrieved from https://wwwgenesis.destatis.de/genesis/online/ (last accessed 2.11.2019).

Thieken, A. H., Bessel, T., Kienzler, S., Kreibich, H., Müller, M., Pisi, S., \& Schröter, K. (2016). The flood of June 2013 in Germany: how much do we know about its impacts?. Nat. Hazards Earth Syst. Sci., 16, 1519-1540. https://doi.org/10.5194/nhess-16-1519-2016

Thieken, A. H., Kreibich, H., Müller, M., \& Lamond, J. (2017). Data collection for a better understanding of what causes flood damage - experiences with telephone surveys. In D. Molinari, S. Menoni, \& F. Ballio (Eds.), Flood damage survey and assessment: New insights from research and practice (Chap. 7, pp. 95-106). Washington, DC: AGU. https://doi.org/10.1002/9781119217930.ch7

Vacondio, R., Aureli, F., Ferrari, A., Mignosa, P., \& Dal Palù, A. (2016). Simulation of the January 2014 flood on the Secchia River using a fast and high-resolution 2D parallel shallow-water numerical scheme. Nat. Hazards, 80, 103-125/ https://doi.org/10.1007/s11069-015-1959-4

Vinet, F., Lumbroso, D., Defossez, S., \& Boissier, L. (2012). A comparative analysis of the loss of life during two recent floods in France: the sea surge caused by the storm Xynthia and the flash flood in Var. Nat. Hazards, 61(3), 1179-1201. https://doi.org/10.1007/s11069011-9975-5

Vogt, J. V., Soille, P., de Jager, A., Rimaviciute, E., Mehl, W., Foisneau, S., Bodis, K., Dusart, K., Paracchini, M.-L., Haastrup, P., \& Bamps, C. (2007). A pan-European River and 
Catchment Database. JRC Reference Report (EUR 22920 EN). Luxembourg:

Publications Office of the European Union. https://doi.org/10.2788/35907

Wagenaar, D., Lüdtke, S., Schröter, K., Bouwer, L. M., \& Kreibich, H. (2018). Regional and temporal transferability of multivariable flood damage models. Water Resour. Res., 54(5), 3688-3703. https://doi.org/10.1029/2017WR022233

Wind, H. G., Nierop, T. M., de Blois, C. J., \& de Kok, J. L. (1999). Analysis of flood damages from the 1993 and 1995 Meuse floods. Water Resour. Res., 35(11), 3459-3466. https://doi.org/10.1029/1999WR900192 